\title{
The E-Scooter Potential to Change Urban Mobility-Belgrade Case Study
}

\author{
Draženko Glavić (D), Ana Trpković (D), Marina Milenković (D) and Sreten Jevremović *(D) \\ Faculty of Transport and Traffic Engineering, University of Belgrade, 11000 Belgrade, Serbia; \\ drazen@sf.bg.ac.rs (D.G.); a.trpkovic@sf.bg.ac.rs (A.T.); marina.milenkovic@sf.bg.ac.rs (M.M.) \\ * Correspondence: s.jevremovic@sf.bg.ac.rs
}

Citation: Glavić, D.; Trpković, A.; Milenković, M.; Jevremović, S. The E-Scooter Potential to Change Urban Mobility-Belgrade Case Study. Sustainability 2021, 13, 5948. https://doi.org/10.3390/su13115948

Academic Editor: Francesca Pagliara

Received: 3 April 2021

Accepted: 19 May 2021

Published: 25 May 2021

Publisher's Note: MDPI stays neutral with regard to jurisdictional claims in published maps and institutional affiliations.

Copyright: (c) 2021 by the authors. Licensee MDPI, Basel, Switzerland. This article is an open access article distributed under the terms and conditions of the Creative Commons Attribution (CC BY) license (https:// creativecommons.org/licenses/by/ $4.0 /)$.

\begin{abstract}
As we witness a global change occurring with the advent of e-scooters (electric scooters), it is clear that adequate measures need to be taken for the implementation of this means of transport. Bearing in mind that the user should be the focus of the proposed measures, the aim of this paper encompasses the analysis of e-scooter users' travel patterns, as well as standard scooter users' willingness to switch to e-scooters for different hypothetical scenarios, and the determination of factors that have an influence on the users' willingness to switch. The scenarios include the availability of various infrastructure capacities for the city of Belgrade, namely, a separate infrastructure for escooters, or sharing the existing infrastructure with cyclists, pedestrians and motor vehicles. Standard methods of descriptive statistics, the McNemar-Bowker test of paired samples, and multinomial logistic regression were used in this paper. The results showed that there was a statistically significant difference in users' willingness to use an e-scooter, depending on the available infrastructure. The results of multinomial logistic regression showed that the mode of transport used before and during the COVID-19 pandemic, as well as the average distance traveled, had a statistically significant impact on the users' willingness to switch to e-scooters if they were allowed to use the cycling infrastructure. This paper also identifies additional factors that have a positive (environmental benefits, congestion avoidance) and negative (safety issues, lack of infrastructure, etc.) impact on users' willingness to switch, which can be of use to decision-makers as a basic guideline for the adequate implementation of e-scooters in transport systems.
\end{abstract}

Keywords: e-scooters; willingness to switch; micromobility; user perception; infrastructure; COVID-19

\section{Introduction}

The concept of mobility can be defined as the physical movement of people and goods, expressed through the number of trips, distance and speed [1]. The mobility of the population, in that sense, is a consequence of various socio-economic factors, most often divided according to the purposes of travel. Accordingly, the largest percentage of daily movements is realized with the purpose of going to/from work, school, university, etc. The remaining daily movements usually include reasons such as going shopping, recreation, leisure, etc. The defined purpose of travel, distance, journey time, area of the city, and demographic characteristics of the population or individuals will impact the choice of the mode of transport. In most cities, the dominant mode of transport is still a car or public transport, with a smaller number of travelers walking and cycling. A significant percentage of cars in the overall modal share makes cities less sustainable and less liveable. The spatial expansion of cities, with the inevitable increase in congestion on the one hand, and the growing need to travel on the other, has conditioned the emergence of different modes of transport with the idea of balancing user requirements and traffic system supply.

The two main representatives of a relatively new wave of mobility are electric bicycles, which have been active on the market for almost two decades, and electric scooters, which have experienced growth in the past few years. These two types of transport belong to 
the micromobility subsystem, which can be defined as the use of small mobility devices, designed to carry one or two people or "last mile" deliveries [2].

The main advantages of these types, primarily e-scooters, are reflected in their characteristics: dimensions, weight, speed, maneuverability, flexibility, etc. These characteristics have enabled e-scooters to position themselves as a suitable solution for "first" and "last mile" travel [3,4]. Given that the car is the dominant mode of transport over short distances (up to $3 \mathrm{~km}$ ), e-scooters, in this sense, could represent an adequate alternative [5]. As a consequence of such use of e-scooters, a commensurate reduction in the use of cars at such distances can be expected. By reducing car usage, with the transfer to e-scooters, the general positive impact on the environment and urban sustainability of cities increases. Given the significant advantages of e-scooters over cars, e.g., environmental friendliness (less noise, reduced emissions), freeing up space, and especially, reducing congestion, there is a clear need and desire to open cities up for this new, sustainable, mode of transport.

An additional advantage of e-scooters, compared to e-bikes, is the ability to modify the dimensions of electric scooters, which makes them adjustable when boarding public transport vehicles. In that way, the realization of multimodal trips, in combination with any subsystem of public transport, is enabled.

In general, the trend of population growth and population migration requires fast and sustainable urban solutions, and an efficient transport system. According to estimates, by 2050 , as much as $68 \%$ of the world's population will be concentrated in urban areas [6], while transportation demands will have almost doubled. Driving a car in such conditions, with the existing infrastructure, would be completely inefficient and even impossible. New modes of transport such as e-scooters, integrated with public transport, have the potential to significantly reduce the use of cars and provide a sustainable transport system.

On the other hand, the use of e-scooters has revealed significant shortcomings, which have brought up many questions and sparked a debate between the proponents of escooter use and their detractors. Perhaps the most frequently emphasized problem is related to safety and injuries caused by the use of e-scooters, suffered by both e-scooter users themselves and other road users [7-10]. However, a large number of additional side effects slow down and reduce all the positive effects that electric scooters bring, such as lack of clear regulations, lack of adequate infrastructure, as well as the inappropriate behavior of electric scooter users [11,12]. A number of countries, such as Germany, France, Singapore, New Zealand, Australia, and California, have fully regulated the use of escooters, while most countries are in transition (such as the UK) or are still without any measures being taken.

By considering all the above characteristics, and in accordance with the individual requirements for movement, each traveler makes a decision on the use of e-scooters. Bearing in mind that these decisions are often not simple, and that in the decision-making process the choice of mode of transport is usually based on the compensation of different characteristics, this paper analyzes the willingness of users to use electric scooters under different conditions and restrictions, and in different scenarios. These scenarios include the offer of a different infrastructure and its impact on the users' willingness. For example, the question is how users would behave if they were permitted to use a segregated infrastructure intended only for e-scooters, or if they shared the infrastructure with cyclists, pedestrians or other motor vehicles. The current road regulations in the Republic of Serbia do not recognize e-scooters and their participation in traffic, nor is the appropriate infrastructure defined for these means of transport. Consequently, the formation of the aforementioned scenarios represents the first step in the process of regulating e-scooters as equal means of transport in traffic. The authors believe that the offer of a diverse infrastructure has a significant impact on the willingness of users to use this means of transport, which is why the paper itself is focused on this issue. The contribution of this paper is based on examining the impact of different infrastructure capacities on e-scooter users, and providing specific guidelines to decision-makers, which can play an important role in the process of development and implementation of e-scooters in transport systems. The two primary 
objectives of this paper are to analyze and determine the willingness of users to switch to the use of e-scooters depending on the defined infrastructure scenarios, and to determine the factors that have an impact on the willingness of users to switch to e-scooters to ensure and promote more sustainable transport modes. In addition to the above, this paper also includes an analysis of e-scooter users, with the goal of determining the behavioral and travel patterns characteristics of these users.

The paper consists of seven chapters, namely, the introductory chapter which presents the basic idea and goal of this paper, the literature review that covers the latest and most interesting results in this area, the multidimensionality of micromobility, the methodology through which the method of analysis used in this paper is explained, the review of the analyzed results, a discussion of the obtained results and the conclusion.

\section{Literature Review}

The e-scooter expansion in America, with over 38.5 million trips in 2018 [13], quickly spread throughout the world. Just two years after breaking into the market, e-scooter services were available in over 630 cities in 53 countries, with over 300 million trips recorded worldwide [14]. The reason for such a rapid acceptance of this new type of transport can be primarily found in its characteristics, which made e-scooters extremely attractive and interesting. This is supported by a survey in Portland, in which as many as $28 \%$ of the respondents said that they used e-scooters solely for visual appeal, entertainment and recreation [15]. It can be assumed that the attractiveness of this type of transport was one of the triggers for its global expansion [16]. Consequently, this led to the successful promotion of e-scooters. For example, a survey conducted in several major US cities at the very beginning of the introduction of e-scooters in traffic showed that as many as $70 \%$ of respondents had a positive opinion about this type of transport [17]. It is important to note that it was only after more intensive use of e-scooters that users were able to get acquainted with the real advantages and disadvantages that this mode of transport provides. Just after this trial period, numerous discussions were launched on how to regulate and use e-scooters in cities.

Viewed from different perspectives, e-scooters can be considered an effective solution to a large number of problems faced by modern cities, but they have also become one of the main problems of these same cities [18]. The great potential of e-scooters is reflected in the possibility of filling the gap between walking and using a car. For example, $24 \%$ of all trips in England are shorter than $3 \mathrm{~km}$ [19], which opens up the possibility of using e-scooters on such routes, and commensurately reducing the use of cars. This is supported by the results of research conducted in several American cities, where as much as $68 \%$ of e-scooter travel is shorter than $1.5 \mathrm{~km} \mathrm{[16].} \mathrm{In} \mathrm{addition,} \mathrm{the} \mathrm{integration} \mathrm{of} \mathrm{e-scooters} \mathrm{and}$ public transport systems provides an adequate alternative to cars for longer distances [20]. This opportunity was exploited by the residents of Paris, where $23 \%$ of e-scooter trips were performed in combination with some other mode of transport. In as many as $66 \%$ of cases, the journey was realized in combination with public transport [21]. It is interesting to note that the same study showed that e-scooters participated in $0.8 \%$ to $1.9 \%$ of the total modal share in Paris. For example, the share of bicycle traffic in the same city is 3\% [21]. A survey conducted for the Helsinki area showed that about $3 \%$ of the total of 14,500 analyzed trips by car did not have an adequate or cost-effective alternative in the form of public transport. In fact, most such trips take up to $1.4 \mathrm{~km}$, with the only alternatives to public transport being walking and cycling. Additionally, about $35 \%$ of the analyzed car trips, which do not have an adequate alternative in the form of public transport, are realized for short distances, up to $500 \mathrm{~m}$ [22]. Such distances, although they may vary, usually include the pedestrian accessibility area, i.e., where walking is the dominant type of movement $[23,24]$. In this particular case, users opted for driving instead of walking, which violates the general concept of sustainability. In such situations, e-scooters could play an important role and fill the gap that exists between walking and driving. This would 
provide users with an efficient, flexible and sustainable form of transport, which combines the positive characteristics of walking and driving.

Certainly, the most important change and impact of e-scooters could be measured through changes in the modal share. The basic idea of e-scooter integration is to enable the efficiency and sustainability of the transport system. In that sense, the significant potential of this type of transport is reflected in the possibility of providing an adequate alternative to a car for shorter distances. The transfer of users from cars to e-scooters is essential. On the other hand, there is a danger that the transfer will be done away from other types/ways of movement such as walking or cycling, which in this case would have the opposite, negative effect. This sequence of circumstances should be avoided. A number of papers have dealt with the aforementioned effect of user migration, with quite different results being obtained. For example, in a survey conducted in Portland, 34\% of residents and $48 \%$ of visitors said that instead of using a car or taxi, they chose an e-scooter. It is interesting to note that as many as $6 \%$ of the respondents were considering giving up a car completely, and buying and using an e-scooter instead [15]. Similar results were obtained in a survey conducted in Santa Monica, where $49 \%$ of the respondents said that car travel was replaced by some form of shared micromobility [25]. In an analysis of the attitudes of users in Arlington, $52 \%$ of the respondents said that they had been using cars, taxi services, Ubers, etc. less frequently since they had started using e-scooters. What is slightly worrying in this study are the higher percentages of users who reduced their cycling $(44 \%)$ and walking $(28 \%)$ due to the use of e-scooters [26]. The research in Hoboken confirmed that most short trips (to shops, markets, restaurants, etc.) were made using e-scooters instead of cars. Of the respondents, $59 \%$ said that the use of e-scooters facilitated access to and movement through the business zone [27]. On the other hand, a study in Denver showed that as many as $43 \%$ of movements realized by walking were replaced by e-scooters, $14 \%$ of bicycle trips were replaced by e-scooter journeys, while only $10 \%$ of car trips were replaced by e-scooter journeys [28]. A survey of the Tempe university staff found that if they could not use the e-scooter, $65 \%$ of respondents would walk, $25 \%$ would travel by car and $8 \%$ by bicycle [29]. The different results of the presented research prevent generalized conclusions, which only indicates the complexity of the presented problem. A large number of factors that can be the cause of the mentioned differences depend on the characteristics of the area, the examinees, the conditions under which the examination was performed, etc., so the conclusions reached should be carefully interpreted. What should definitely be mentioned here, and what is common to certain research, are the significant percentages of e-scooter movements that are performed for the purpose of going to/from work. In Santa Monica, this accounts for $29 \%$ of all e-scooter movements, while in Denver that share is as much as $32 \%[28,30]$.

Due to the current circumstances, the unfavorable situation at a global level, caused by the appearance of the COVID-19 virus, also led to drastic changes in the traffic system. So far, the mass-use public transport subsystem has become the most unsafe form of travel. People were more focused on individual modes of transport and walking, which gave additional space for a greater use of e-scooters. In fact, the decline in the use of micromobility during May was significantly smaller compared to the decline in car and public transport usage, while the use of e-scooters is expected to increase in the coming months [31].

In general, the expansion of micromobility, and e-scooters with it, took place in several waves, out of which only the first wave was planned and considered [32]. The remaining two waves brought negative consequences and shortcomings with them, and opened up many questions. The shortcomings refer to regulations, the problems of space and infrastructure, safety and injuries caused by the use of e-scooters, user behavior, etc. Although a large number of countries have already drafted and adopted the necessary regulations, manuals and guidelines for managing and improving micromobility [33-35], most of the negative consequences are still there. Injuries caused by the use of e-scooters are still common, especially accidents involving pedestrians $[36,37]$. An example is the aforementioned 
research conducted in Arlington, in which as many as $25 \%$ of the respondents said that, as pedestrians, they did not feel safe in the presence of e-scooter users [26]. The behavior of e-scooter users is also a poor advertisement for this mode of transport. Non-compliance with traffic regulations, passing through a red light, traveling on the sidewalk, driving in the opposite direction, non-compliance with the age limit for the use of e-scooters, not wearing a protective helmet, etc. $[25,27,38]$, are just some of the issues that are often reported to the authorities. There is much controversy about parking, i.e., the occupation of space by e-scooters, although this statement was refuted in a recent study, which showed that only $1.1 \%$ of e-scooters blocked a passage or had a negative impact on the effective width of pedestrian passages [39].

All the examples presented so far indicate that there are no universal formulas or standard solutions that will treat the specific problems of e-scooters, nor can their integration into the existing traffic system be performed according to the same principle. Each area and city, according to its needs, characteristics and available data, must treat the existing local problem in order to reach an equilibrium of all users and traffic participants [40].

\section{Multidimensionality of Micromobility}

At the very beginning of this study, it is important to emphasize the multidimensionality provided by the use of e-scooters, which is why these devices have become widely adopted around the world. In the next seven subchapters, the most significant impacts of e-scooters will be briefly explained from the aspects of mobility, infrastructure, traffic safety, legislation, economy, ecology and COVID-19. This chapter explains the positive and negative changes that e-scooters have caused, not only in traffic but also in everyday life.

\subsection{The Ecology Dimension}

Probably one of the most significant characteristics of e-scooters is their environmental efficiency. Although the overall production process (battery production in the first instance) has a negative impact on the environment, the general impact of e-scooters compared to internal combustion vehicles is potentially smaller. The carbon footprint of e-scooters has rapidly reduced since their initial implementation, showing a $70 \%$ reduction in $\mathrm{CO} 2 \mathrm{per} \mathrm{km}$, since January 2019. [41]. Similar to all other electric vehicles (cars, bicycles, etc.), e-scooters reduce congestion, have zero emission as they do not emit air pollutants, and are also quiet, thus having no influence on the noise pollution levels in cities [42,43] Significant reductions in carbon emissions can potentially be achieved if e-scooters replace internal combustion vehicles, i.e., if the short journeys that are made by car are accomplished by e-scooters. For example, the use of an e-scooter causes between 64 and $237 \mathrm{~g}$ of $\mathrm{CO}_{2}$, which can be further reduced by 20-30\% after two years. Compared to a standard car that emits 147 to $414 \mathrm{~g}$ of $\mathrm{CO}_{2}$, e-scooters provide a more environmentally friendly option [44]. Replacing internal combustion vehicles, as one of the biggest pollutants in traffic, with e-scooters provides a multi-benefit solution. One of the main preconditions is that using e-scooters as a tool to achieve sustainable transport in cities requires their availability to as many social groups as possible [45]. For this reason, e-scooters must be equally accessible to everyone.

The first important aspect and benefit of this replacement is the energy efficiency of e-scooters. For example, one kilowatt-hour of energy could drive a gasoline-powered vehicle for about $1.2 \mathrm{~km}$. The Tesla Model 3 can travel for about $6.5 \mathrm{~km}$ using the same amount of energy, and an e-scooter can travel for more than $125 \mathrm{~km} \mathrm{[46]} \mathrm{However,} \mathrm{as}$ already mentioned, it is important to have a clear picture of where the energy came from.

Another equally significant aspect is the possibility of short trips, as well as first and last mile realization with e-scooters. For example, in the UK, 58\% of car trips are shorter than $8 \mathrm{~km}$, and in urban environments, 69\% of car trips are shorter than $5 \mathrm{~km}$. Considering that the typical distances of e-scooter trips are $1.5-8 \mathrm{~km}$, there is evident potential for e-scooters to replace cars within cities and reduce every negative consequence that arises with their use [41]. Moreover, in Paris, the average city speed for the last mile of a journey 
is $16 \mathrm{kph}$. With typical legal speeds of 20-30 kph, e-scooters have the ability to decrease journey times over short urban trips, and can thus be used for last mile trips [41].

Overall, the basic characteristics of e-scooters classify them as an eco-friendly mode of transport. The direction in which this mode will develop and the way in which it will contribute to the preservation of eco-sustainability largely depends on the engagement of all entities at all state levels. The research and results of this paper aim to show the potential impact of e-scooters on the modal split in Belgrade. Given the significant share of cars in the modal split, the transition of users to e-scooters can significantly contribute to the development and maintenance of a clean and environmentally friendly urban environment.

\subsection{The Mobility Dimension}

In addition to their existing advantages regarding speed and the ability to avoid congestion, the main potential of the e-scooter is reflected in maintaining multimobility. For example, a study conducted in Indianapolis found that, in the three months that the analysis covered, more than 425,000 trips were made, and more than 765,000 km was covered. These data indicate that, on average, about 4830 trips per day were made by e-scooters. The average journey length in this case was $1.8 \mathrm{~km}$ [47]. Here we can potentially see the main advantages of this type of transport. At the beginning of the expansion of e-scooters, it was hypothesized that travelers making $0.8-3.2-\mathrm{km}$ trips would probably accrue the greatest benefits from them [5], which has been confirmed on several occasions. The biggest contribution of e-scooters and micromobility overall is in their role as part of the MaaS initiative, which could be the perfect solution for filling the gap between walking and using public transport.

In general, the use of e-scooters for the last and first mile can largely replace the use of a private vehicle over shorter distances. As can be seen from Figure 1, the first and primary mode of transport is a private vehicle. This type of modal share should definitely be avoided. With so many cars on the road network, negative consequences increase, which is why there is a tendency to reduce their use. In this sense, e-scooters can play a very important role at shorter distances.

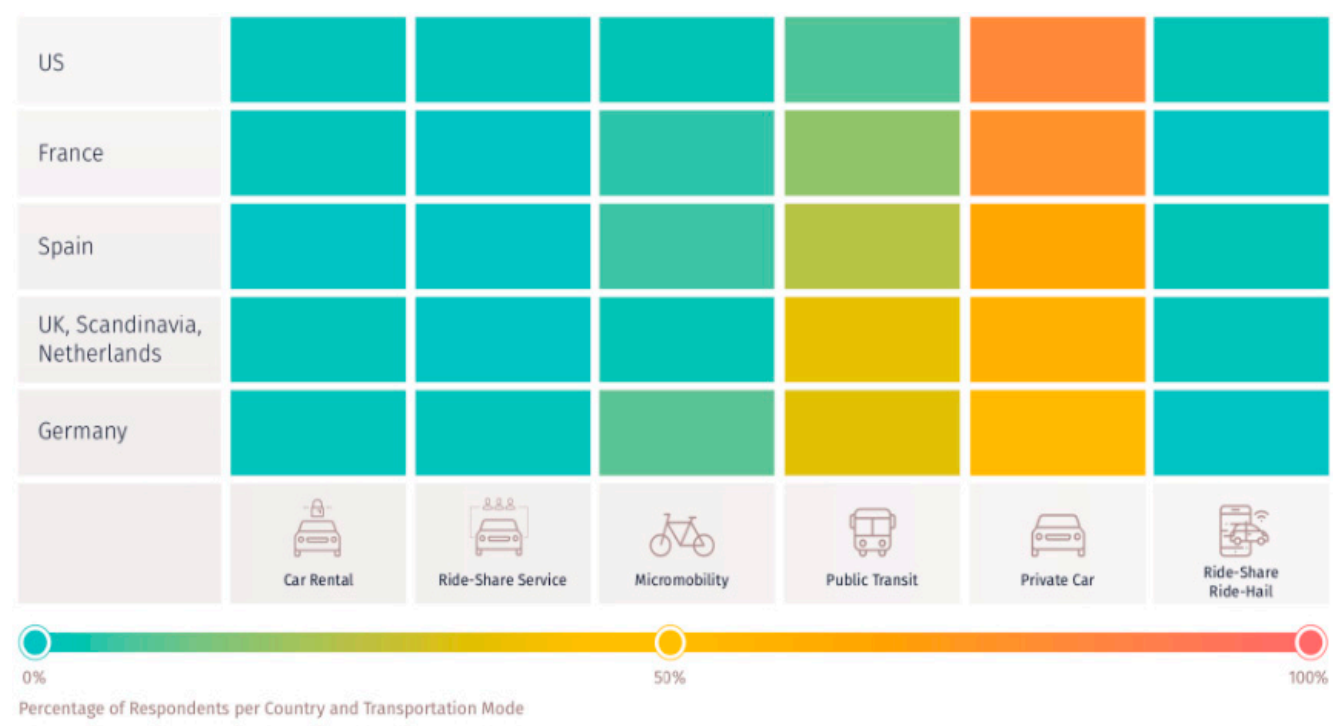

Figure 1. Primary transportation mode heatmap. Source: https:/ / oobrien.com/2019/09/the-state-of-mobility/ (Accessed date: 6 September 2020).

In addition, the integration of the e-scooter with public transport provides an adequate alternative to driving over long distances. Given the possibility of loading e-scooters on public transport vehicles, the establishment of multimodal transport is further facilitated in this way. Thus, an increasing number of researchers and decision-makers are recognizing and promoting e-scooters and micromobility as a promising mode of transportation. 
However, what is important to note here is the countereffect that should be avoided. Although the idea is to reduce the number of cars on the road network and redirect a certain number of car users to the adoption of e-scooters, the opposite can happen very easily. We do not want users from other active and sustainable modes of transport such as walking and cycling to shift to e-scooters. This effect would not provide any benefits to the traffic system itself, while the existing problems would remain unresolved.

\subsection{The Infrastructure Dimension}

The basic precondition for the efficient functioning of e-scooters is an adequate infrastructure. Currently, this is one of the most important issues that micromobility is facing. The physical limitations of the street network and road profile, the different structures and characteristics of the base surfaces, and the existing separation represent obstacles for the safe usage of e-scooters. Traffic experts worldwide agree that streets with a surface made of cobblestones or slabs, as well as streets with tramway tracks, are not safe for e-scooter riding. The characteristics of these vehicles, primarily their small wheel circumference and radius, limit their use on the abovementioned surfaces. Although a large number of countries have started introducing amendments to the law in order to properly handle this transportation mode, insufficient attention is still paid to infrastructure development and modification.

In the countries and cities where the arrangement and adaptation of urban space has already begun, e-scooter users are mostly redirected to the cycling infrastructure. Such examples can be found in Tel Aviv, Paris, and most American cities. In London, the government intends to legalize the use of e-scooters primarily in business zones, parks and campuses. Company Voi in Sweden plans to introduce "Zones 20", where e-scooters would be allowed to travel. The city of Copenhagen intends to introduce and test 200 electric scooters in the historic city center, as well as 3000 e-scooters in satellite zones [48]. For instance, in Texas, it is permitted to ride e-scooters on sidewalks, while in Colorado, sidewalks are the only places where they can be used. In California, it is strictly forbidden to ride e-scooters on sidewalks, but riding is allowed on the carriageway along the right curb of the sidewalk. In reality, the situation is considerably different, and e-scooters are frequently ridden on sidewalks in spite of the prohibitions and warnings that this compromises traffic safety. It is important to note that in Europe, about $65 \%$ of the countries that have regulated or are in the process of regulating the use of e-scooters have allowed their use on the cycling infrastructure.

Generally speaking, two diametrically opposed concepts of infrastructure arrangement include either physically segregated lanes for this mode of transport, or a concept such as a shared space, both shown in Figure 2. For example, a two-way dedicated cycleway can carry about 4.6 times more people per hour than a standard 3-m wide vehicle lane [49]. Bearing in mind that e-scooters could potentially use the same infrastructure, with the same technical characteristics, there is a possibility that this mode of transport can achieve similar space-time benefits [50].

The two concepts mentioned above have their advantages, but present two completely opposite approaches. At the moment, cities face both the exponential growth of e-scooter numbers in the street network and a lack of space, so the solution could lie somewhere between these two concepts and could result in their combination and coordination. Currently, most cities are opting to redirect e-scooters to the cycling infrastructure, which in a sense may be the active solution. Given the increasing use of this type of transport in traffic, it is necessary to pay attention to additional measures and the arrangement of infrastructure, whether it is their integration with cyclists or separation from the remaining traffic. 

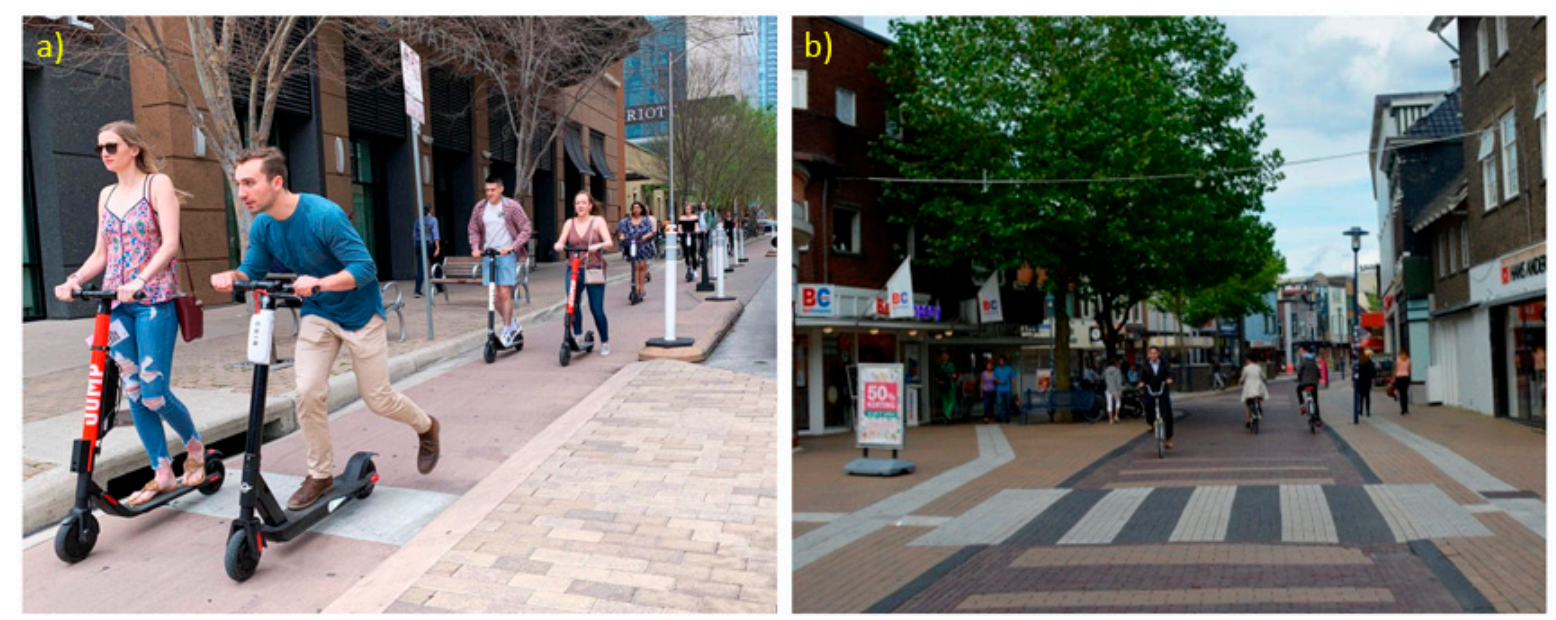

Figure 2. (a) Segregated infrastructure for e-scooters, (b) shared space design for all users. Source: https://www.theverge. com and https: / / www.cycling-embassy.org.uk (Accessed date: 13 September 2020).

\subsection{The Traffic Safety Dimension}

In spite of their many advantages, electric scooters have aroused strong public opposition. The main opponents of this transportation mode are usually cyclists and pedestrians, who are placed under pressure due to the need for sharing the infrastructure and the fact that their safety is jeopardized. Pedestrians are generally the most vulnerable category of road users, since in most countries riding e-scooters on sidewalks has not yet been regulated by law. As a consequence, traffic accidents involving pedestrians are very frequent. It was the endangerment of pedestrians that led cities, in which the use of e-scooters is regulated, to prohibit their movement on the sidewalks.

For example, in 2018, approximately 1500 recorded injuries were caused by the use of e-scooters, and eight people were killed in 47 American cities [51]. The main problem is that this number is constantly rising.

A study conducted in Austin, Texas, over a period of three months (from September to November 2018) found that 271 people had been injured as a consequence of using e-scooters. A more thorough analysis showed that during the observed three-month period, for every 100,000 trips by e-scooter, 20 people were injured. In the total sample, $58 \%$ of those injured were users younger than 30 . Head trauma (48\% of the respondents) and fractures $(35 \%)$ were the most frequent injuries. It is important to mention that out of the total number of injured riders, $62 \%$ were novice users, while only $4 \%$ of the users wore a helmet while riding [52]. The situation is not any different in European countries and cities. For example, in France, Britain and Germany, dozens of people were injured in 2019 [53].

Bearing in mind these findings, numerous countries have already regulated the use of e-scooters, while in others, certain companies, organizations and associations offer only recommendations related to using e-scooters, for example wearing a helmet, reducing the driving speed or driving slowly, avoiding driving on bumpy surfaces, etc. These recommendations are treated as part of the system of pre-legislative activities until amendments to the law or new laws are adopted. Given the large number of accidents that occur, cities must react quickly. It is very important to address the use of e-scooters in the right way, and legally provide support and a basis for the safe development of this type of micromobility. Otherwise, completely different effects could be achieved than those advantages related to using e-scooters.

\subsection{The Legislative Dimension}

The expansion of e-scooters has found many cities unprepared and without an adequate response to this change. A large number of cities are still struggling with the problem of regulation, and how to include e-scooters in the already existing traffic laws. Frequently asked questions refer to the categorization of e-scooters, adequate space for their use, the 
obligations and rights of users, etc. Many cities have already made significant changes and adjustments to their regulations, which have to some extent contributed to the introduction of the e-scooter as an equal subsystem in the transport network.

For example, in Britain, it is illegal to ride electric scooters on public roads, sidewalks, bicycle lanes and paths. In addition, an e-scooter rider has to be at least 14 years old [54]. E-scooter riders are fined $£ 300$ and 6 penalty points on their driver's license. Consequently, the exponential growth of e-scooters and the changes that came with them induced active measures on the improvement of legislation in Great Britain.

Some countries such as France and Germany have already defined or are currently classifying a new vehicle group (PLEVs-"personal light electric vehicles") [55]. Electric scooters are treated as PMD ("personal mobility devices") in Singapore, while in Poland there is an initiative for amendments to the law, in order to introduce a new vehicle category (PTD-“"personal transport device") [56].

California was one of the first states that regulated the use of e-scooters. For example, the user has to possess a driver's license, and use of the cycling infrastructure (paths of class II and IV) is allowed at the maximum speed of $25 \mathrm{~km} / \mathrm{h}$. It is permitted to ride an e-scooter on streets with a $40 \mathrm{~km} / \mathrm{h}$ speed limit, but only if the e-scooter moves at a speed of up to $25 \mathrm{~km} / \mathrm{h}$. They are also permitted for use on roads with a speed limit of up to $56 \mathrm{~km} / \mathrm{h}$, with the previous permission of the authorities. In this case, the speed of the e-scooter must not exceed the $25 \mathrm{~km} / \mathrm{h}$ speed limit [57].

As in the majority of countries, there are no regulations regarding the use of e-scooters in Serbia. However, certain amendments to the existing law on road traffic safety have been announced. The Road Traffic Safety Agency has proclaimed that the amendments to the law will start some time in 2021. Until then, the users are only offered the experts' recommendations, which are mainly related to the use of protective helmets and the careful operation of e-scooters. In addition to all the changes that have been made, and a clear desire for improvement, a large number of irregularities such as traffic accidents and inadequate user behavior are still present. This only indicates the scope and complexity of the existing problem, which will require persistent and continuous actions for its solution.

\subsection{The Economic Dimension}

The e-scooter market has shown enormous growth in an extremely short time. For example, the global electric scooter market size has recently been valued at US $\$ 17.43$ billion and is expected to have a compound annual growth rate of $8.5 \%$ over the next 10 years [58]. When it comes to the economic benefits of using an e-scooter, two characteristic aspects can be distinguished: the benefits realized by users, and the benefits realized by operators. Given the e-scooter market growth, the benefits of the operator are clear. The costs and benefits incurred by users differ depending on the ownership and the way the e-scooter is used. It is interesting to note that in some cities, the use of e-scooters per ride is more expensive than public transport, walking or cycling [42].

One of the significant advantages of this type of transport is the price range of escooters, which makes them affordable for different income categories. Moreover, the additional maintenance does not require significant costs, especially considering the charging of the e-scooter, which can be done at any location that meets the basic requirements for charging mobile phones. This advantage, for example, is significant when compared to electric vehicles, which usually require a special charging infrastructure.

\subsection{The COVID-19 Dimension}

The outbreak of COVID-19, which has spread throughout the world, has greatly changed the way we have lived, worked, traveled and behaved until now. The specificity of this situation is reflected in the fact that not only the modal share but also the safety of certain modes of transport has completely changed. For example, public transport, which is being developed with the aim of establishing a sustainable and efficient transport system, is most affected, especially bearing in mind the impossibility of adequate physical 
distancing in public vehicles. Various aspects, including the COVID-19 impact trend, do not promise the secure recovery of the public transport subsystem as it is now. On the other hand, individual modes of transport, such as bicycles, electric bicycles, electric scooters and cars, have emerged to be safety-efficient in this situation. Therefore, e-scooters are given another important advantage, and that is the possibility of realizing the trip while maintaining physical distance.

Consequently, micromobility and e-scooters can play a significant role in developing and maintaining the efficiency of the transport system in the forthcoming period, especially if the current trend of COVID-19 prevents a significant recovery of public transport.

\section{Research Methodology}

\subsection{Data Collection}

For the purposes of this paper, a questionnaire was formed, which was used for the collection of respondents' attitudes. The inhabitants of Belgrade, the capital of the Republic of Serbia, represented the target group. The research was conducted within a three-month period from July to September 2020. An online survey was conducted in order to respect health and safety guidelines during the COVID-19 pandemic. The online survey was distributed as a link via email. After the incomplete questionnaires with inconsistent responses had been removed from the total sample, the valid sample used in the further analysis consisted of 1143 respondents. Inconsistency was determined using control questions. The questionnaire was divided into four parts (see Table 1). The first part of the questionnaire contained general questions about the demographic and socio-economic characteristics of the respondents. The second section covered the users' attitudes and patterns of behavior, examined through the average distance traveled, their mode of transport before and during the pandemic for different trip purposes, their mode substitution for an e-scooter, the frequency of e-scooter use, their personal safety regarding e-scooter usage when sharing the infrastructure with other users, and a potential combination of the e-scooter and public transport for daily trips. In this paper, the following purposes were chosen, those of going to work/school, visiting, shopping, recreation and leisure, while the chosen modes of transport were a private vehicle, public transport, walking, a bicycle and an e-scooter. The structure of the two questions mentioned is defined so as to cover the most common purposes for travel, as well as the most common modes of transport.

The third section of the questionnaire consisted of two questions, in which the goal was to determine which factors positively and negatively affected the drivers' willingness to use e-scooters. Some of the positive factors selected for the purposes of this research included the avoidance of traffic jams, shorter travel time or physical distancing. The negative factors were a lack of regulations, a lack of infrastructure, bad weather, mandatory vehicle registration, etc. These are shown in Table 1 . The fourth part of the questionnaire was divided into four scenarios, and analyzed the respondents' willingness to shift to e-scooters for their chosen travel purposes in different scenarios. All four scenarios include various infrastructure options that would be available to users, as follows:

- a dedicated infrastructure designed exclusively for e-scooters;

- the infrastructure that e-scooter users would share with pedestrians: sidewalks, footpaths and other pedestrian areas;

- the infrastructure that e-scooter users would share with bicycle users: bicycle paths and bicycle lanes;

- the infrastructure that e-scooter users would share with other motor vehicles: the road or carriageway. 
Table 1. Questionnaire structure.

1st section: Users' socio-demographic and economic characteristics

\section{Gender}

(a) Female, (b) Male

Age

(a) $\leq 18$, (b) 18-25, (c) 26-35, (d) 36-45, (e) 46-55, (f) 56-65, (g) >65

Education

(a) Non-graduate, (b) graduate

Employment status

(a) Permanently employed, (b) occasionally employed, (c) student, (d) retiree, (e) unemployed

Average monthly income

a) $<€ 250,(b) € 250-500,(c) € 501-750$, (d) $€ 751-1000,(e)>€ 1000$, (f) No income

2nd section: Users' attitudes and pattern behavior

What is the average distance you travel in one direction for the following trip purposes? (Work/school; visit; shopping; recreation; leisure)

(a) $<0.5 \mathrm{~km},($ b) $0.5-1 \mathrm{~km}$, (c) $1-2 \mathrm{~km}$, (d) $2-3 \mathrm{~km},($ e) $3-5 \mathrm{~km},(f) 5-8 \mathrm{~km},(\mathrm{~g})>8 \mathrm{~km}$

What way of movement/mode of transport did you most often use BEFORE the COVID-19 pandemic occurred for the stated purposes? (Work/school; visit; shopping; recreation; leisure)

(a) Private vehicle, (b) public transport, (c) walking, (d) bicycle, (e) e-scooter

What way of movement/mode of transport did you most often use DURING the COVID-19 pandemic for the stated purposes?

(Work/school; visit; shopping; recreation; leisure)

(a) Private vehicle, (b) public transport, (c) walking, (d) bicycle, (e) e-scooter

For which mode of transport did you substitute an e-scooter for the following trip purposes? (Work/school; visit; shopping; recreation; leisure)

(a) Private vehicle, (b) public transport, (c) walking, (d) bicycle

How often do you use an e-scooter for the following trip purposes? (Work/school; visit; shopping; recreation; leisure)

(a) I do not use an e-scooter for the defined purpose, (b) several times a year, (c) several times a month, (d) several times a week, (e) daily

How would you rate your own safety if you shared the infrastructure with the following users? (a five-step scale was used for

this question: very safe, safe, not sure, unsafe, very unsafe)

(a) Pedestrians, (b) cyclists, (c) motor vehicles

Do you combine the use of an e-scooter and public transport when traveling for the following trip purposes? (Work/school;

visit; shopping; recreation; leisure)

(a) Never, (b) rarely, (c) sometimes, (d) often, (e) always

3rd section: Factors that have a positive/negative impact on non-users' willingness to use an e-scooter

To what extent do the following factors POSITIVELY affect your willingness to use an electric scooter? (1-not at all influential, 2-slightly influential, 3-I am not sure, 4-very influential, 5-extremely influential)

(a) Avoiding traffic jams, (b) transportation cost savings, (c) shorter time of travel, (d) physical distancing, (e) environment protection, $(f)$ affordability, $(g)$ flexibility, $(h)$ attractiveness

To what extent do the following factors NEGATIVELY affect your willingness to use an electric scooter? (1-not at all influential, 2-slightly influential, 3-I am not sure, 4-very influential, 5-extremely influential)

(a) Lack of regulation, (b) lack of adequate infrastructure, (c) sharing space with other users, (d) weather: rain, snow, wind etc. (e) feeling unsafe when using the road with other motor vehicles, $(f)$ discomfort: limited luggage space, standing while driving, etc.

(g) Mandatory registration and insurance of e-scooters, (i) mandatory safety helmet, retroreflective clothing, e-scooter lighting, ( $j$ ) speed limit

4th section: Users' willingness to use an e-scooter for different travel purposes (work/school; visit; shopping; recreation;

leisure) in different scenarios

Would you shift to e-scooters if there were a dedicated infrastructure designed exclusively for e-scooters?

(a) No, (b) maybe, (c) yes

Would you shift to e-scooters if you had to share the infrastructure with pedestrians (use a sidewalk, footpaths and other pedestrian areas)?

(a) No, (b) maybe, (c) yes

Would you shift to e-scooters if you had to share the infrastructure with bicycle users (use bicycle paths and lanes)?

(a) No, (b) maybe, (c) yes

Would you shift to e-scooters if you had to share the infrastructure with other motor vehicles (use the carriageway)?

(a) No, (b) maybe, (c) yes

The defined scenarios represent hypothetical cases that aim to determine the attitudes and preferences of users about the desired infrastructure. However, the baseline scenario includes the current regulations in the Republic of Serbia that do not recognize the use of e-scooters or define a specific infrastructure for them. For this reason, the authors believe 
that the answers to these questionnaires can provide useful knowledge and set the basis for improving and forming adequate legislation.

All questions were of the closed-ended type, while for the third section of the questionnaire a five-step Likert scale was used, as shown in Table 1. In order to obtain the most accurate responses from the respondents, primarily those who were not certain regarding their decision about shifting from other transport modes to e-scooters, in the fourth part of the questionnaire the respondents were offered the answer "maybe", in addition to "yes" and "no". In this manner, we excluded the possibility of a number of users being forced to answer "yes" or "no".

In this paper, we combined two approaches: a revealed preference and a stated preference method. We used the first method to analyze the existing habits of the respondents regarding the use of a particular transport mode for different travel purposes, while the second approach was employed to analyze the users' preferences regarding the use of e-scooters for a hypothetical situation (scenarios as previously mentioned in the paper).

\subsection{Variables and Statistical Analysis}

The data were analyzed using IBM SPSS 22. We used standard methods of descriptive statistics, the McNemar-Bowker test of paired samples, and multinomial logistic regression. The following ten hypotheses have been established:

Hypothesis 1 (H1). There is a statistically significant difference in the share of respondents who would switch to the use of e-scooters with the availability of different infrastructure.

Hypothesis 2 (H2). There is a statistically significant difference in the degree of e-scooter use during the COVID-19 pandemic compared to the period before the pandemic.

Hypothesis 3 (H3). The users' gender has a statistically significant impact on their willingness to start using e-scooters for commuting trips.

Hypothesis 4 (H4). The users' age has a statistically significant impact on their willingness to start using e-scooters for commuting trips.

Hypothesis $\mathbf{5}$ (H5). The users' level of education has a statistically significant impact on their willingness to start using e-scooters for commuting trips.

Hypothesis 6 (H6). The users' employment status has a statistically significant impact on their willingness to start using e-scooters for commuting trips.

Hypothesis 7 (H7). The users' income has a statistically significant impact on their willingness to start using e-scooters for commuting trips;

Hypothesis 8 (H8). The transport mode previously used by the users has a statistically significant impact on their willingness to start using e-scooters for commuting trips.

Hypothesis 9 (H9). The distance traveled by the users has a statistically significant impact on their willingness to start using e-scooters for commuting trips.

Hypothesis 10 (H10). There is a statistically significant impact of user perception on the importance of certain characteristics regarding the users' willingness to use e-scooters.

In this paper, multinomial logistic regression (MLR) was carried out in order to estimate how well a set of predictors predicted or explained the categorical dependent variable-the users' willingness to switch to e-scooters for commuting trips if different types of infrastructure were available or provided. This approach, rather than a binary model, is required in this paper because of the number of available discrete outcomes-the 
users who would definitely use (or not use) the e-scooters, and the users who might start using e-scooters for commuting trips. The MLR model is an extension of multiple regression modeling, where the dependent variable is discrete instead of continuous, enabling the modeling of discrete outcomes. In particular, we were interested in characterizing the probability of individual choices depending on the values of different factors. We used gender, age, level of education, employment status, average monthly income, the transport mode used before and during the COVID-19 pandemic, the average distance traveled, and positive and negative factors that have a potential impact on users' willingness to use e-scooters. All the stated variables are categorical, except the positive and negative impact factors, which are continuous. The reference category, with which the results would be compared, was required, so those who would not start using e-scooters were selected to represent the reference category of the dependent variable. The reference groups for each independent variable were selected on the basis of the dominant categories of the users in Belgrade. The reference groups for the final model presented in this paper are public transport for the type of transport used before the pandemic and during the pandemic, while for the average distance traveled, the reference group includes average distances from 5 to $8 \mathrm{~km}$.

Multinomial logistic regression has been widely used in papers dealing with the analysis of traffic crashes, injuries of traffic participants $[59,60]$ or prediction of the specific behavior of road users [61,62]. Coughenour et al. [63] used MLR to determine the types of infrastructure which were perceived as safe and most likely to be used by traffic users. Festa \& Forciniti [64] analyzed the conditions under which users would agree to use bicycles for different trip purposes. In addition to those mentioned above, a variety of papers used MLR to analyze the quality and level of service for customers provided by the public transport systems $[65,66]$.

\section{Results}

This chapter presents the most significant and interesting results obtained by analyzing the collected data. The chapter is divided into three parts for the sake of simplicity and comprehensibility of the obtained results. The first part presents the basic characteristics of the sample, as well as the demographic and socio-economic characteristics of the respondents. The second part presents the users' pattern behavior before and during the COVID-19 pandemic, with an emphasis on e-scooter use. The last chapter includes the results that show the users' willingness to switch to the use of e-scooters for the selected scenario, users' attitudes towards positive and negative aspects of e-scooter usage, and factors that have an impact on the users' willingness to transfer to an e-scooter.

\subsection{Sample Characteristics}

For the purposes of this research, a sample of 1143 respondents was collected, involving the defined categories as shown in Table 2. In this sample, the participation of men and women was almost equal, and amounted to $53 \%$ of females versus $47 \%$ of males. When it came to age, the most represented category included the respondents aged 19-25 $(44.9 \%)$. The proportion of the graduate respondents was slightly larger $(56 \%)$ than the proportion of non-graduate respondents (44\%). The largest proportion of the respondents was permanently employed (40.6\%). In terms of the average monthly income, most of the respondents had no income (31\%), followed by those with a monthly income of $€ 250-500$ $(21 \%)$. Having in mind the proportion of men and women in the total population in Belgrade (52.6\% women and $47.4 \%$ men), as well as the average income for 2019 of $€ 582$, it can be concluded that the characteristics of the sample correspond to the general characteristics of the population in Belgrade. 
Table 2. Demographic and socio-economic characteristics of the respondents.

\begin{tabular}{|c|c|c|}
\hline Respondents Characteristics & $\mathbf{n}$ & $\%$ \\
\hline \multicolumn{3}{|l|}{ Gender } \\
\hline Female & 602 & 52.7 \\
\hline Male & 541 & 47.3 \\
\hline \multicolumn{3}{|l|}{ Age } \\
\hline$\leq 18$ & 57 & 5.0 \\
\hline $19-25$ & 513 & 44.9 \\
\hline $26-35$ & 310 & 27.1 \\
\hline $36-45$ & 102 & 8.9 \\
\hline $46-55$ & 91 & 8.0 \\
\hline $56-65$ & 42 & 3.7 \\
\hline$\geq 65$ & 28 & 2.4 \\
\hline \multicolumn{3}{|l|}{ Education level } \\
\hline Non-graduate & 505 & 44.2 \\
\hline Graduate & 638 & 55.8 \\
\hline \multicolumn{3}{|l|}{ Employment status } \\
\hline Permanently employed & 464 & 40.6 \\
\hline Occasionally employed & 133 & 11.6 \\
\hline Student & 427 & 37.4 \\
\hline Retiree & 46 & 4.0 \\
\hline Unemployed & 73 & 6.4 \\
\hline \multicolumn{3}{|l|}{ Income } \\
\hline No income & 351 & 30.7 \\
\hline$<€ 250$ & 131 & 11.5 \\
\hline$€ 250-500$ & 236 & 20.6 \\
\hline$€ 501-750$ & 207 & 18.1 \\
\hline$€ 751-1.000$ & 104 & 9.1 \\
\hline$>€ 1.000$ & 114 & 10.0 \\
\hline
\end{tabular}

\subsection{Existing E-Scooter Users' Pattern Behavior}

In this analysis, the following trip purposes were observed: going to/from work/school, visiting, shopping, recreation and leisure. The use of e-scooters for the observed purposes was analyzed, depending on the defined time periods before and during the pandemic. Figure 3 shows the percentage use of e-scooters for different trip purposes, according to the observed time periods.

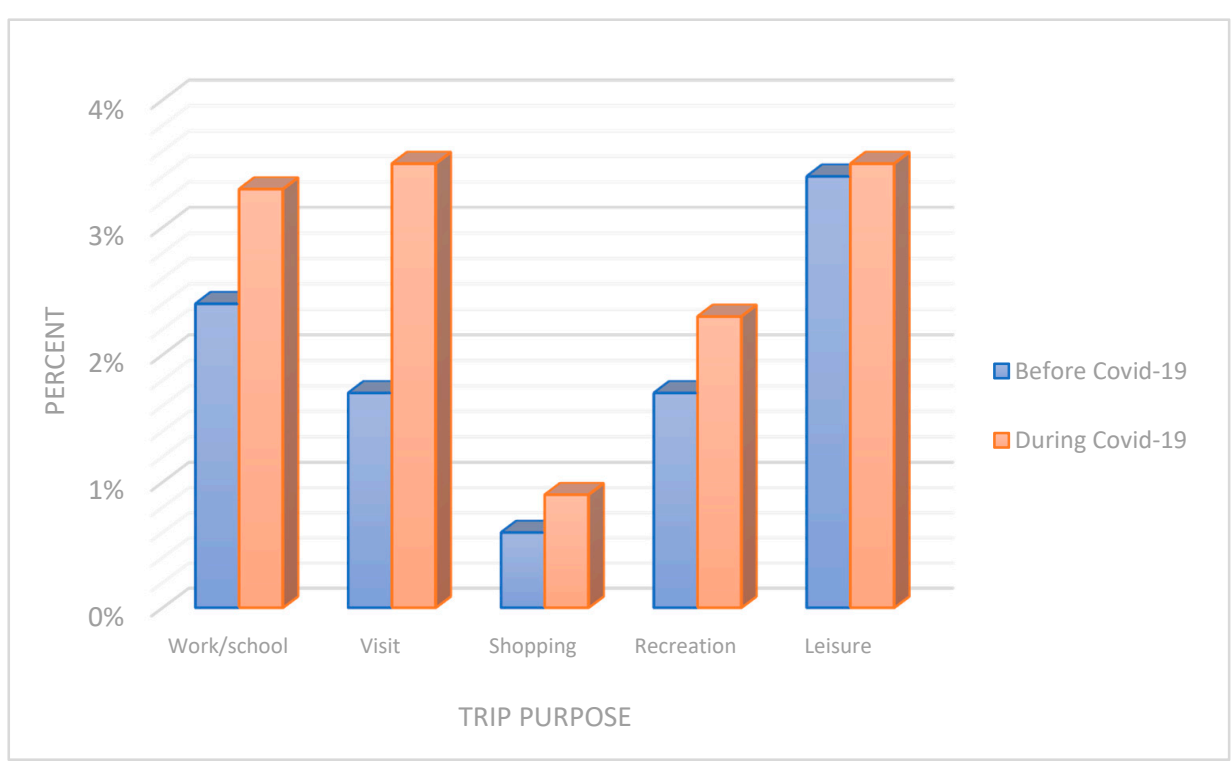

Figure 3. Changes in the use of e-scooters for different trip purposes in the two analyzed time periods. 
Figure 3 shows an increase in the use of e-scooters in the modal share during the pandemic, regardless of the travel purpose. Such results are expected, particularly due to the previously mentioned advantages that e-scooters have. McNemar's test showed a statistically significant difference in the use of e-scooters for the period during the pandemic, compared to the period before the pandemic, for three of the five defined purposes, namely, work/school trips $(p=0.006)$, trips with the purpose of a visit $(p<0.001)$ and recreational trips $(p=0.039)$. Based on the above, the hypothesis $\mathrm{H}_{2}$ can be accepted.

Bearing in mind the importance and proportion of commuting trips in the daily trip distribution, the basic characteristics of e-scooter use for the purpose of going to/from work/school will be briefly presented in the following text.

- Males use e-scooters more $(61 \%)$ compared to females.

- The largest share of e-scooter users are people aged 18-25 (39\%).

- Generally, graduate respondents use e-scooters slightly more than non-graduate ones (54\% compared to $46 \%$ ).

- Permanently employed respondents have the highest share of e-scooter use (57\%), compared to the other employment categories.

- Interestingly, the respondents with an average income of more than $€ 1000$ per month have the highest proportion of e-scooter usage (29\%) compared to the other income categories.

- In most cases, e-scooters are used for leisure purposes. It is important to note that out of the total number of respondents, $41 \%$ of them used the e-scooter every day for the purpose of going to/from work/school. On average, e-scooters are most often used several times a month.

- $\quad$ Figure 4 shows modes of transport that were substituted by e-scooters for the defined trip purposes. It is important to note that on average, most users did not substitute a specified mode of transport by an e-scooter. The largest number of users that changed their mode of transport (26.5\%) replaced their car with the e-scooter. Public transport was replaced by $16.7 \%$ of the users, while e-scooters replaced walking in the case of $15 \%$ of the users. In general, the smallest percentage of replacement is recorded for bicycle users $(4.1 \%)$.

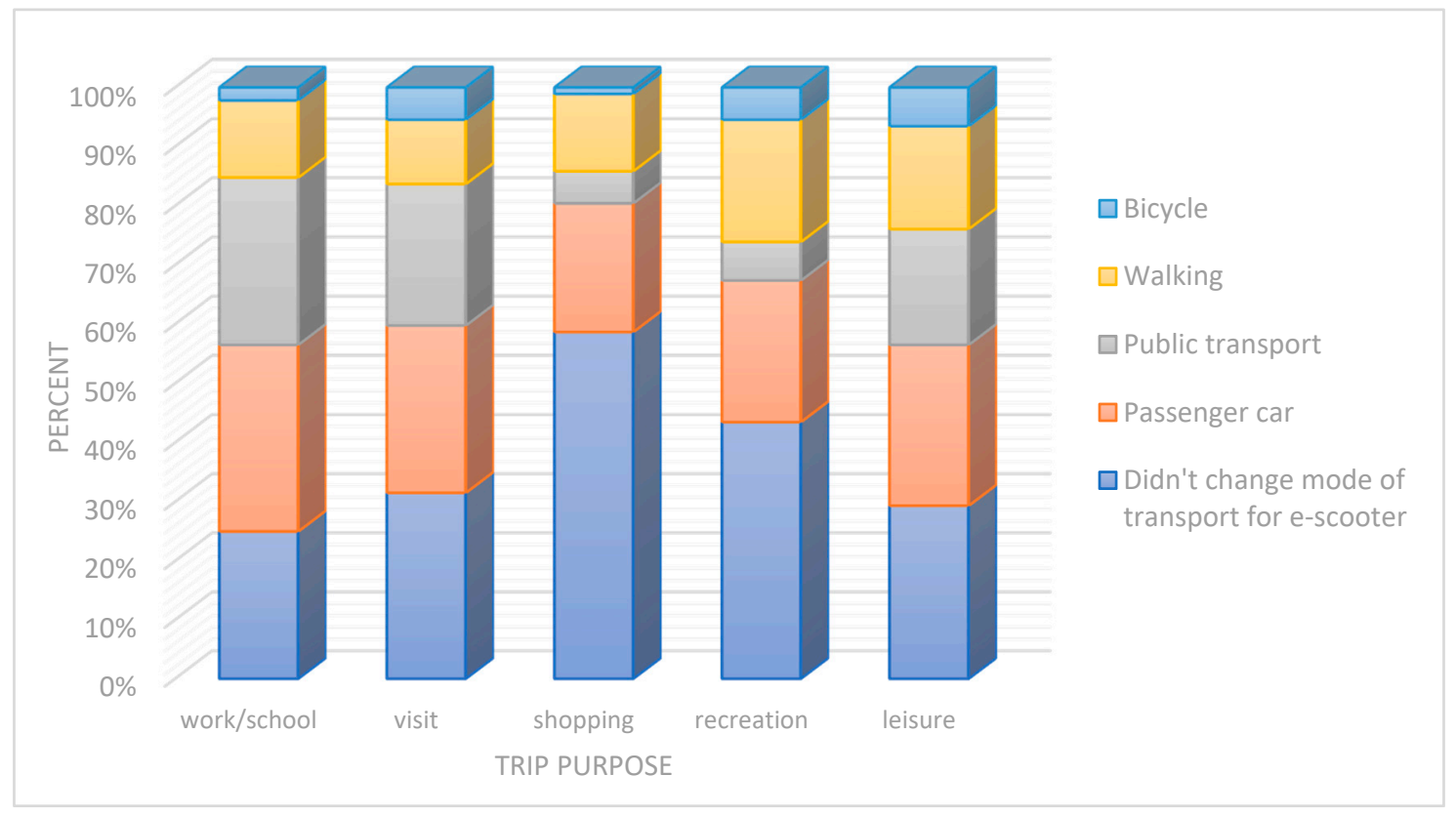

Figure 4. Mode of transport that was substituted by e-scooters for the specified trip purposes. 
- E-scooters are mostly used (43\%) by the respondents that travel on average 3.0 to $5.0 \mathrm{~km}$ to work or school.

- Regarding traffic safety in the case of sharing the infrastructure with other users, e-scooter users commented as follows: $78.7 \%$ of them stated that they would feel safe sharing the infrastructure with pedestrians, $96.4 \%$ would feel safe sharing the infrastructure with cyclists, and 50\% would feel safe sharing the infrastructure with motor vehicles.

- A significant number of e-scooter users emphasized that the introduction of this means of transport would certainly not be deterred by the introduction of additional measures such as a speed limit for electric scooters, a mandatory safety helmet, registration, insurance, and mandatory e-scooter lights or retroreflective clothing.

- It is also interesting to note that more than half of the respondents (53.6\%) never or rarely combined the use of e-scooters and public transport.

\subsection{Users' Willingness to Use an E-Scooter}

This chapter is divided into two parts. The first part shows the results of the users' willingness to switch to e-scooters, depending on the offered infrastructure, for the defined trip purposes. The second part presents the results of the multinomial logistic regression model. This model was used to examine the impact of the defined variables on the users' willingness to use e-scooters for commuting trips, and the scenario where they were permitted to share the infrastructure with cyclists. This scenario is used as the best case realistic scenario, considering the users' responses presented in this paper, as well as the experience of foreign countries in the process of regulating, defining, and implementing an infrastructure for e-scooters.

\subsubsection{Willingness to Switch to E-Scooters for Different Scenarios}

As mentioned in the methodology section, the willingness of users to use e-scooters was analyzed through four potential scenarios. The scenarios include the availability of a different infrastructure that users can use for the defined trip purposes. Table 3 shows the results of the conducted analysis.

Table 3. Users' willingness to use an e-scooter for different trip purposes in the defined scenarios.

\begin{tabular}{|c|c|c|c|c|c|c|c|c|c|c|c|}
\hline \multirow{2}{*}{ Defined Scenarios } & \multirow{2}{*}{ Proposed Answers } & \multicolumn{2}{|c|}{ Work/School } & \multicolumn{2}{|c|}{ Visit } & \multicolumn{2}{|c|}{ Shopping } & \multicolumn{2}{|c|}{ Recreation } & \multicolumn{2}{|c|}{ Leisure } \\
\hline & & $\mathbf{n}$ & $\%$ & $\mathbf{n}$ & $\%$ & n & $\%$ & n & $\%$ & $\mathbf{n}$ & $\%$ \\
\hline \multirow{3}{*}{$\begin{array}{l}\text { Separate infrastructure for } \\
\text { e-scooters }\end{array}$} & No & 394 & 39.2 & 290 & 27.6 & 391 & 37.3 & 359 & 34.2 & 293 & 27.9 \\
\hline & Maybe & 515 & 51.2 & 643 & 61.3 & 578 & 55.1 & 561 & 53.5 & 598 & 57.0 \\
\hline & Yes & 96 & 9.6 & 116 & 11.1 & 80 & 7.6 & 129 & 12.3 & 158 & 15.1 \\
\hline \multirow{3}{*}{$\begin{array}{l}\text { Infrastructure shared with } \\
\text { pedestrians }\end{array}$} & No & 459 & 45.7 & 385 & 36.7 & 452 & 43.1 & 426 & 40.6 & 372 & 35.5 \\
\hline & Maybe & 482 & 48.0 & 596 & 56.8 & 547 & 52.1 & 544 & 51.9 & 591 & 56.3 \\
\hline & Yes & 64 & 6.4 & 68 & 6.5 & 50 & 4.8 & 79 & 7.5 & 86 & 8.2 \\
\hline \multirow{3}{*}{ Infrastructure shared with bicycles } & No & 379 & 37.7 & 318 & 30.3 & 402 & 38.3 & 356 & 33.9 & 308 & 29.4 \\
\hline & Maybe & 538 & 53.5 & 642 & 61.2 & 584 & 55.7 & 603 & 57.5 & 640 & 61.0 \\
\hline & Yes & 88 & 8.8 & 89 & 8.5 & 63 & 6.0 & 90 & 8.6 & 101 & 9.6 \\
\hline \multirow{3}{*}{$\begin{array}{c}\text { Infrastructure shared with motor } \\
\text { vehicles }\end{array}$} & No & 627 & 62.4 & 615 & 58.6 & 645 & 61.5 & 610 & 58.2 & 584 & 55.7 \\
\hline & Maybe & 343 & 34.1 & 397 & 37.8 & 369 & 35.2 & 397 & 37.8 & 421 & 40.1 \\
\hline & Yes & 35 & 3.5 & 37 & 3.5 & 35 & 3.3 & 42 & 4.0 & 44 & 4.2 \\
\hline
\end{tabular}

Users are most willing to switch to the use of e-scooters when there is a separate infrastructure available, then within the scenario of sharing an infrastructure with cyclists, followed by sharing the sidewalk with pedestrians, and are least willing when sharing the road network with other traffic, regardless of the trip purpose.

McNemar-Bowker test showed that the differences in the willingness of users to switch to the use of e-scooters, depending on the proposed infrastructure for all travel purposes, were statistically significant in almost all cases, which partly proves the first 
hypothesis $\mathrm{H}_{1}$. The exceptions are the differences in the case of separate infrastructure and sharing infrastructure with cyclists for trips to work/school $(p=0.323)$ and shopping trips $(p=0.141)$. At this point, it is important to emphasize the similarity of the willingness of users to switch to the use of e-scooters in the situations where they have an available separate infrastructure, or the infrastructure that they would share with cyclists in case of commuting trips and journeys with the purpose of going shopping.

5.3.2. Determining the Factors Affecting Users' Willingness to Switch to E-Scooters for Commuting Trips, in the Case of Sharing the Infrastructure with Cyclists

At the beginning of this chapter, it is important to note certain socio-economic and traffic differences between the respondents in terms of their willingness to use e-scooters (see Table 4). For the sake of simplicity, only the results of the willingness of users to switch to the use of e-scooters for the purpose of going to/from work/school will be mentioned, in a situation when they are permitted to share the infrastructure with cyclists.

As can be seen from Table 4, only two of the eight analyzed characteristics did not show a statistically significant impact: gender and transport mode used during COVID-19 pandemic.

Table 4. Descriptive statistics and the results of the chi-square test of independence.

\begin{tabular}{|c|c|c|c|c|c|}
\hline \multirow{3}{*}{ Characteristics } & \multicolumn{3}{|c|}{ Infrastructure Shared with Cyclist for } & \multirow{3}{*}{ Chi-Square Value } & \multirow{3}{*}{$p$-Value } \\
\hline & & rk/School Tr & & & \\
\hline & Yes (\%) & Maybe (\%) & No $(\%)$ & & \\
\hline \multicolumn{6}{|l|}{ Gender } \\
\hline Female & 8.4 & 55.5 & 36.1 & \multirow[t]{2}{*}{3.224} & \multirow{2}{*}{0.199} \\
\hline Male & 9.1 & 51.3 & 39.6 & & \\
\hline \multicolumn{6}{|l|}{ Age } \\
\hline$\leq 18$ & 17.0 & 47.2 & 35.8 & \multirow{6}{*}{60.471} & \multirow{6}{*}{$<0.001$} \\
\hline$\overline{19}-25$ & 9.3 & 53.5 & 37.1 & & \\
\hline $26-35$ & 6.3 & 57.4 & 36.3 & & \\
\hline $36-45$ & 10.1 & 55.1 & 34.8 & & \\
\hline $46-55$ & 10.0 & 45.0 & 45.0 & & \\
\hline $56-65$ & 0.0 & 48.4 & 51.6 & & \\
\hline \multicolumn{6}{|l|}{ Education level } \\
\hline Non-graduate & 10.7 & 52.1 & 37.2 & \multirow{2}{*}{18.602} & \multirow[t]{2}{*}{$<0.001$} \\
\hline Graduate & 7.4 & 54.5 & 38.1 & & \\
\hline \multicolumn{6}{|l|}{ Employment status } \\
\hline Permanently employed & 7.5 & 50.2 & 42.2 & \multirow{4}{*}{85.362} & \multirow{4}{*}{$<0.001$} \\
\hline Occasionally employed & 11.2 & 63.2 & 25.6 & & \\
\hline Student & 9.6 & 53.4 & 37.0 & & \\
\hline Unemployed & 7.0 & 56.3 & 36.6 & & \\
\hline \multicolumn{6}{|l|}{ Income } \\
\hline No income & 8.3 & 55.1 & 36.6 & \multirow{6}{*}{36.057} & \multirow{6}{*}{$<0.001$} \\
\hline$<€ 250$ & 10.9 & 56.3 & 32.8 & & \\
\hline$€ 250-500$ & 10.6 & 60.8 & 28.6 & & \\
\hline$€ 501-750$ & 8.3 & 49.4 & 42.2 & & \\
\hline$€ 751-1.000$ & 2.2 & 52.8 & 44.9 & & \\
\hline$>€ 1.000$ & 10.8 & 37.6 & 51.6 & & \\
\hline \multicolumn{6}{|l|}{ Average distance traveled } \\
\hline$<0.5 \mathrm{~km}$ & 5.7 & 61.4 & 33.0 & \multirow{7}{*}{51.687} & \multirow{7}{*}{0.001} \\
\hline $0.5-1 \mathrm{~km}$ & 9.8 & 51.8 & 38.4 & & \\
\hline $1-2 \mathrm{~km}$ & 9.6 & 55.9 & 34.6 & & \\
\hline $2-3 \mathrm{~km}$ & 10.5 & 55.9 & 33.6 & & \\
\hline $3-5 \mathrm{~km}$ & 9.1 & 63.6 & 27.3 & & \\
\hline $5-8 \mathrm{~km}$ & 9.4 & 55.0 & 35.6 & & \\
\hline$>8 \mathrm{~km}$ & 7.2 & 42.4 & 50.4 & & \\
\hline
\end{tabular}


Table 4. Cont.

\begin{tabular}{|c|c|c|c|c|c|}
\hline \multirow{3}{*}{ Characteristics } & \multicolumn{3}{|c|}{ Infrastructure Shared with Cyclist for } & \multirow{3}{*}{ Chi-Square Value } & \multirow{3}{*}{$p$-Value } \\
\hline & & rk/School Tr & & & \\
\hline & Yes $(\%)$ & Maybe (\%) & No $(\%)$ & & \\
\hline \multicolumn{6}{|c|}{ Transport mode used before COVID-19 } \\
\hline Car & 5.1 & 47.6 & 47.3 & & \\
\hline Public transport & 9.3 & 58.3 & 32.4 & 20.571 & 0.002 \\
\hline Walking & 10.5 & 54.2 & 35.3 & & \\
\hline Bicycle & 8.0 & 56.0 & 36.0 & & \\
\hline \multicolumn{6}{|c|}{ Transport mode used during COVID-19 } \\
\hline Car & 6.3 & 52.2 & 41.5 & & \\
\hline Public transport & 9.8 & 56.7 & 33.4 & 10.238 & 0.115 \\
\hline Walking & 9.6 & 56.4 & 33.9 & & \\
\hline Bicycle & 10.8 & 43.2 & 45.9 & & \\
\hline
\end{tabular}

Further analysis showed that certain groups of users are more willing to switch to the use of e-scooters for the purpose of going to/from work/school if they are allowed to share the infrastructure with bicycle users. For example, males are more willing to switch to e-scooters than females. Respondents younger than 18 are generally more prone to switching compared to other age categories, which is shown through the results in Table 5. Non-graduate respondents are more willing to switch to e-scooters than the graduate respondents. In addition, the largest percentage of the respondents $(11.2 \%)$ that would certainly switch to the use of e-scooters, compared to other groups of respondents, are the occasionally employed. Analyzing the average distance traveled, it can be seen that the distribution of users who would certainly switch to the use of e-scooters is almost even. The exceptions are the shortest and longest distances, where a lower percentage of respondents was recorded. The largest percentage was of users who walked to/from work/school before the COVID-19 pandemic, and would certainly switch to the use of e-scooters. However, during the pandemic, the highest percentage of respondents who would switch to the use of e-scooters was recorded among cyclists. In general, people who used cars were least prone to change, regardless of the occurrence of the pandemic.

Table 5 presents the results of the factors that would affect users' willingness to switch to an e-scooter for work/school trips if they were allowed to share the infrastructure with cyclists.

The results in Table 5 show that the environmental protection factor has the biggest positive impact on the users' willingness to use e-scooters, which is reflected in the highest mean value. The factor of avoiding traffic congestion has a similar value and influence. It is interesting to note that factors such as physical distancing, accessibility and attractiveness have lower mean values than other factors, which indicates their smaller positive impact.

On the other hand, there is a much more pronounced influence of certain factors that negatively affect the willingness of users to use e-scooters. The negative factors with the highest average values are mostly related to infrastructure and traffic safety, as well as the general deficiencies of e-scooters when driving in bad weather conditions.

It is also important to note the factors that have the lowest average values, such as a mandatory safety helmet, retroreflective clothing, e-scooter lighting and speed limits for e-scooters. These factors are related to the potential management and regulatory measures that could be introduced. Given the low average values of these factors, it can be assumed that they do not have a significant negative impact on the users' willingness to switch to e-scooters, which can allow the easier regulation of this mode of transport.

Bearing in mind the importance and share of the commuting trips in the daily distribution of journeys, in this paper the results of the final MLR model will be presented only for those trips with the purpose of going to/from work/school. The model also covers the best case and most realistic scenario, i.e., the possibility of e-scooter users sharing the infrastructure with cyclists. This analysis is based on the following statements: 
- Having in mind the current traffic, economic and spatial characteristics of Belgrade, it can be assumed that the chosen scenario is the most realistic.

- Numerous countries in the world that have regulated the use of e-scooters have enabled their users to utilize the cycling infrastructure. In the absence of the same, certain countries allow the use of roads, sidewalks and other surfaces. Most European countries (as mentioned in Section 3.4) allow the use of the cycling infrastructure. The situation is similar to most federal states of America, Australia, Singapore, etc.

Table 5. Positive and negative characteristics influencing users' willingness to use an e-scooter for work/school trips, if e-scooter users were allowed to share the infrastructure with cyclists.

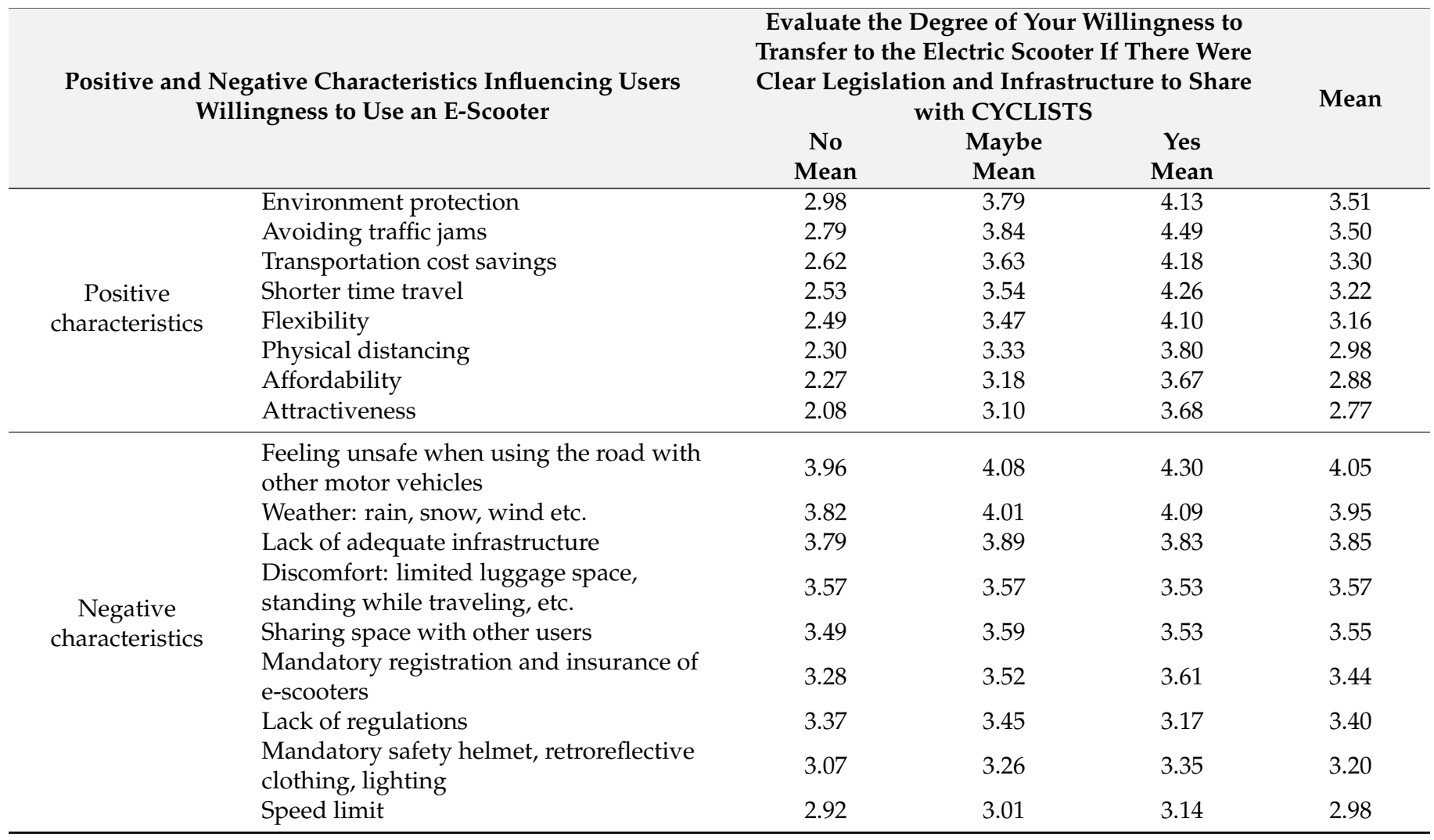

The preliminary model included the variables which had been determined in the previous analysis to have a statistically significant correlation with the users' willingness to shift from other transport modes to e-scooters. Thus, this model involved variables such as gender, age, level of education, employment status, income, the transport mode used before and during the COVID-19 pandemic, the average distance traveled and the positive and negative impact factors described in Section 5.3 of this paper. The obtained results showed that the preliminary model had a greater predictive power than the null model $\left(x^{2}=2181.693, p<0.001\right)$, and that it explained $38.4 \%$ of the variance of the dependent variable $\left(R^{2}=0.384\right)$. However, not all the variables were statistically significant. Therefore, a final model was defined which included only those variables which had been confirmed to be statistically significant in the preliminary model, such as the transport mode used before and during the COVID-19 pandemic, the average distance traveled, and positive and negative impact factors (see Table 6 ). The final model had a greater predictive power than the null model $\left(\chi^{2}=318.613, p<0.001\right)$, and it explained $32.4 \%$ of the variance of the dependent variable $\left(R^{2}=0.324\right)$. 
Table 6. The final MLR model of users' willingness to switch to e-scooters for the defined scenario.

\begin{tabular}{|c|c|c|c|c|c|}
\hline Ref. No & Characteristic & Wald (Z) & $p$ Value & Odds Ratio & $95 \%$ CI \\
\hline \multirow{24}{*}{ Maybe } & Intercept & 14.644 & 0.000 & & \\
\hline & Positive impact factors & & & & \\
\hline & Avoiding traffic jams & 9.936 & 0.002 & 1.263 & $1.092-1.461$ \\
\hline & Transportation cost savings & 6.698 & 0.010 & 1.222 & $1.050-1.421$ \\
\hline & Physical distancing & 3.965 & 0.046 & 1.147 & $1.002-1.312$ \\
\hline & Affordability & 5.035 & 0.025 & 1.194 & $1.023-1.394$ \\
\hline & Attractiveness & 5.980 & 0.014 & 1.185 & $1.034-1.358$ \\
\hline & Negative impact factors & & & & \\
\hline & Feeling unsafe when using the road with other motor vehicles & 6.027 & 0.014 & 0.857 & $0.757-0.969$ \\
\hline & Transport mode used before COVID-19 (Ref. PT) & & & & \\
\hline & Driving & 12.836 & 0.000 & 0.425 & $0.266-0.679$ \\
\hline & Walking & 2.188 & 0.139 & 0.614 & $0.321-1.172$ \\
\hline & Bicycle & 2.612 & 0.106 & 3.470 & $0.767-15.686$ \\
\hline & Average Distance Traveled (Ref. $5.0-8.0 \mathrm{~km}$ ) & & & & \\
\hline & $<0.5 \mathrm{~km}$ & 0.712 & 0.399 & 1.380 & $0.653-2.915$ \\
\hline & $0.5-1.0 \mathrm{~km}$ & 0.001 & 0.979 & 1.009 & $0.511-1.994$ \\
\hline & $1.0-2.0 \mathrm{~km}$ & 0.570 & 0.450 & 1.278 & $0.676-2.414$ \\
\hline & $2.0-3.0 \mathrm{~km}$ & 0.018 & 0.893 & 1.039 & $0.594-1.817$ \\
\hline & $3.0-5.0 \mathrm{~km}$ & 1.122 & 0.290 & 1.381 & $0.760-2.511$ \\
\hline & $>8 \mathrm{~km}$ & 9.897 & 0.002 & 0.456 & $0.279-0.744$ \\
\hline & Transport mode used during COVID-19 (Ref. PT) & & & & \\
\hline & Driving & 1.776 & 0.183 & 1.392 & $0.856-2.263$ \\
\hline & Walking & 0.132 & 0.716 & 1.132 & $0.581-2.206$ \\
\hline & Bicycle & 4.408 & 0.036 & 0.272 & $0.081-0.917$ \\
\hline \multirow{24}{*}{ Yes } & Intercept & 49.863 & 0.000 & & \\
\hline & Positive impact factors & & & & \\
\hline & Avoiding traffic jams & 17.200 & 0.000 & 2.091 & $1.476-2.964$ \\
\hline & Transportation cost savings & 3.053 & 0.081 & 1.284 & $0.970-1.700$ \\
\hline & Physical distancing & 0.992 & 0.319 & 1.124 & $0.893-1.416$ \\
\hline & Affordability & 6.006 & 0.014 & 1.396 & $1.069-1.824$ \\
\hline & Attractiveness & 9.368 & 0.002 & 1.422 & $1.135-1.782$ \\
\hline & Negative impact factors & & & & \\
\hline & Feeling unsafe when using the road with other motor vehicles & 0.203 & 0.652 & 0.943 & $0.731-1.217$ \\
\hline & Transport mode used before COVID-19 (Ref. PT) & & & & \\
\hline & Driving & 7.340 & 0.007 & 0.306 & $0.130-0.721$ \\
\hline & Walking & 0.036 & 0.850 & 1.119 & $0.348-3.596$ \\
\hline & Bicycle & 0.189 & 0.664 & 1.629 & $0.180-14.705$ \\
\hline & Average Distance Traveled (Ref. $5.0-8.0$ km) & & & & \\
\hline & $<0.5 \mathrm{~km}$ & 0.947 & 0.331 & 0.493 & $0.119-2.048$ \\
\hline & $0.5-1.0 \mathrm{~km}$ & 0.068 & 0.794 & 0.855 & $0.264-2.772$ \\
\hline & $1.0-2.0 \mathrm{~km}$ & 0.000 & 0.997 & 0.998 & $0.343-2.899$ \\
\hline & $2.0-3.0 \mathrm{~km}$ & 0.002 & 0.968 & 1.019 & $0.406-2.556$ \\
\hline & $3.0-5.0 \mathrm{~km}$ & 0.019 & 0.891 & 1.072 & $0.398-2.889$ \\
\hline & $>8 \mathrm{~km}$ & 2.652 & 0.103 & 0.495 & $0.212-1.154$ \\
\hline & Transport mode used during COVID-19 (Ref. PT) & & & & \\
\hline & Driving & 0.009 & 0.926 & 1.039 & $0.464-2.325$ \\
\hline & Walking & 0.080 & 0.778 & 0.846 & $0.264-2.706$ \\
\hline & Bicycle & 0.586 & 0.444 & 0.529 & $0.103-2.702$ \\
\hline
\end{tabular}

Reference groups for the following characteristics: transport mode used before COVID-19-public transport, transport mode used during

the pandemic - public transport, and average distance traveled-average distances from $5 \mathrm{~km}$ to $8 \mathrm{~km}$.

The comparison between those who would "possibly" start using e-scooters and those who would not start using e-scooters for commuting trips was as follows.

- With each higher rating given to the congestion avoidance factor, users have a higher chance to "possibly" start than not to start using e-scooters $(p=0.002)$.

- With each higher rating given to the cost savings factor, users have a higher chance to "possibly" start than not to start using e-scooters $(p=0.010)$.

- With each higher rating given to the physical distancing factor, users have a higher chance to "possibly" start than not to start using e-scooters $(p=0.046)$. 
- With each higher rating given to the "affordability of e-scooters" factor, users have a higher chance to "possibly" start than not to start using e-scooters $(p=0.025)$.

- With each higher rating given to the attractiveness factor, users have a higher chance to "possibly" start than not to start using e-scooters $(p=0.014)$.

- With each higher rating given to the traffic safety factor, users have a lower chance to "possibly" start than not to start using e-scooters $(p=0.014)$.

- In comparison to the respondents who used public transport as the main transport mode before the pandemic, the respondents who used private vehicles have a smaller chance to "possibly" start than not to start using e-scooters $(p<0.001)$.

- In comparison to the respondents who traveled an average distance of 5.0 to $8.0 \mathrm{~km}$, the respondents who traveled an average distance of more than $8 \mathrm{~km}$ have a smaller chance to "possibly" start than not to start using e-scooters $(p=0.002)$.

- In comparison to the respondents who used public transport during the pandemic as the main transport mode, the respondents who used bicycles have a smaller chance to "possibly" start than not to start using e-scooters $(p=0.036)$.

The comparison between those who stated that they would "definitely" start using e-scooters and those who would definitely not start using e-scooters for commuting trips was as follows.

- With each higher rating given to the congestion avoidance factor, users have a higher chance to start using e-scooters $(p<0.001)$.

- With each higher rating given to the "affordability of e-scooters" factor, users have a higher chance to start using e-scooters $(p=0.014)$.

- With each higher rating given to the attractiveness factor, users have a higher chance to start using e-scooters $(p=0.002)$.

- In comparison to the respondents who used public transport as the main transport mode before the pandemic, the respondents who used private vehicles have a smaller chance to start using e-scooters $(p=0.007)$.

\section{Discussion}

The results presented in this paper indicate several significant factors that can play an important role in the process of e-scooter regulation and a definition of their place in an urban and sustainable traffic system. First of all, the COVID-19 pandemic has affected various aspects of life to a greater or lesser extent, of which the negative consequences and impacts on traffic are probably the most visible. In order to combat the pandemic, a large number of countries have decided to introduce measures to restrict the movement of people. The introduced measures most affected public transport, which experienced a smaller or larger decline in use depending on the area [67]. With this in mind, users have focused on the modes of transport that provide a certain level of physical distance. The results presented in this paper indicate a statistically significant difference in the use of e-scooters during the pandemic for three out of five trip purposes, compared to the period before the pandemic, which confirms hypothesis $\mathrm{H}_{2}$. In fact, the largest increases were recorded for the purposes of going to/from work/school, and trips with the purpose of visiting $-36 \%$ and $100 \%$, respectively. These results indicate the potential of e-scooters to respond to rapid changes in the traffic system and adapt to user requirements as a consequence of the COVID-19 pandemic. In addition to e-scooters, there has been an increase in the use of bicycles and walking for certain journey types, which suggests that users tend to rely on alternative modes of transport in such situations. The presented results indicate the awareness and the need for people to turn to traffic-sustainable and safer modes of transport in such situations, in which e-scooters, i.e., micromobility vehicles in general, can play an important role.

When it comes to e-scooter user characteristics, as well as the travel patterns of these users, it was found that they largely coincide with the already established general characteristics. For example, a study in Greece showed that females were less keen on using e-scooters than males [68]. A study in Portland [15] also found that men used e- 
scooters more than women for work trips ( $22 \%$ of males, compared to $15 \%$ of females), which coincides with the results presented in this paper. In addition, the largest number of e-scooter users from this research are people under the age of 35, which coincides with a survey conducted in France [21]. The main share of e-scooter users are full-time employees with a degree, which concurs with the research conducted in Vienna [69]. In this paper, the results showed that e-scooters are most often used for working trips with an average distance of 3.0 to $5.0 \mathrm{~km}$. These results match the average distance covered by US users, which is $3.2 \mathrm{~km}$ [70]. The presented data indicate the significant potential of escooters to replace the use of private vehicles, taxis, etc., for traveling shorter distances [71]. In the analysis of the abovementioned socio-economic, demographic and travel pattern characteristics, only two of the eight characteristics do not show statistically significant results. In other words, gender and the transport mode used during the pandemic do not have a statistically significant impact on users' willingness to use an e-scooter for work/school trips, in the scenario of sharing the infrastructure with cyclists. This confirms the hypotheses $\mathrm{H}_{4}, \mathrm{H}_{5}, \mathrm{H}_{6}, \mathrm{H}_{7}, \mathrm{H}_{8}$, and $\mathrm{H}_{9}$, while hypothesis $\mathrm{H}_{3}$ is rejected.

In the analysis of various factors that can have a positive and negative impact on the willingness of users to switch to e-scooters, general similarities were found among the attitudes of users in various studies. In this paper, the following factors have the greatest positive impact on the willingness of drivers to use e-scooters: environmental protection, avoidance of congestion, transport cost savings and shorter travel time. Very similar results were obtained in a study conducted in the city of Tempe in Arizona [29]. The respondents in this research stated the main advantages to be travel speed in relation to walking, the convenience of using this type of transport, providing an adequate replacement for a car, lower transportation costs, environmental protection, etc. (Tempe). All the positive influencing factors presented so far indicate the advantages of e-scooters, in terms of their technical characteristics and advantages that can be achieved when traveling shorter distances. On the other hand, the factors that have a negative impact on the willingness of users to switch to e-scooters are related to the lack of infrastructure and user safety in such situations. These are the general problems faced by users of this type of transport, which is confirmed by research conducted in Saudi Arabia, Portland and Arizona [15,29,72].

In general, the presented positive and negative factors play an important role in the decision-making process, regulation and manner of implementation of e-scooters in traffic systems. The presented negative factors point to the need to provide an adequate and safe infrastructure for these users, which will remove the basic obstacles to their participation in traffic. On the other hand, attention should be paid to maintaining the positive impact of certain factors. For example, it is necessary to maintain the competitiveness of e-scooters on shorter distances, while keeping the proportion of time spent walking but reducing the use of cars. In that sense, e-scooters can have a significant place in the modal share, and fill the gap that exists between walking and public transport.

Figure 5 shows the potential use of e-scooters for different trip purposes if users were permitted to use the bicycle infrastructure, compared to the usage before COVID-19, when no infrastructure regulations were in place.

Figure 5 shows a significant increase in the users' willingness to switch to e-scooters regardless of the travel purpose, in the scenario of sharing the infrastructure with cyclists. It is important to note that Figure 5 encompasses the users who would "definitely" switch to the use of e-scooters if they were provided with a cycling infrastructure. A potentially large group also includes the users who would "probably" switch to the use of e-scooters if the mentioned infrastructure were available. In this sense, decision-makers must focus the proposed measures and activities on both groups of users, especially taking into account the requirements of users who are still unsure of their decision whether to use e-scooters. For that reason, it is necessary to select future measures and activities very carefully, because their choice can greatly influence indecisive users' willingness to switch to e-scooters. 


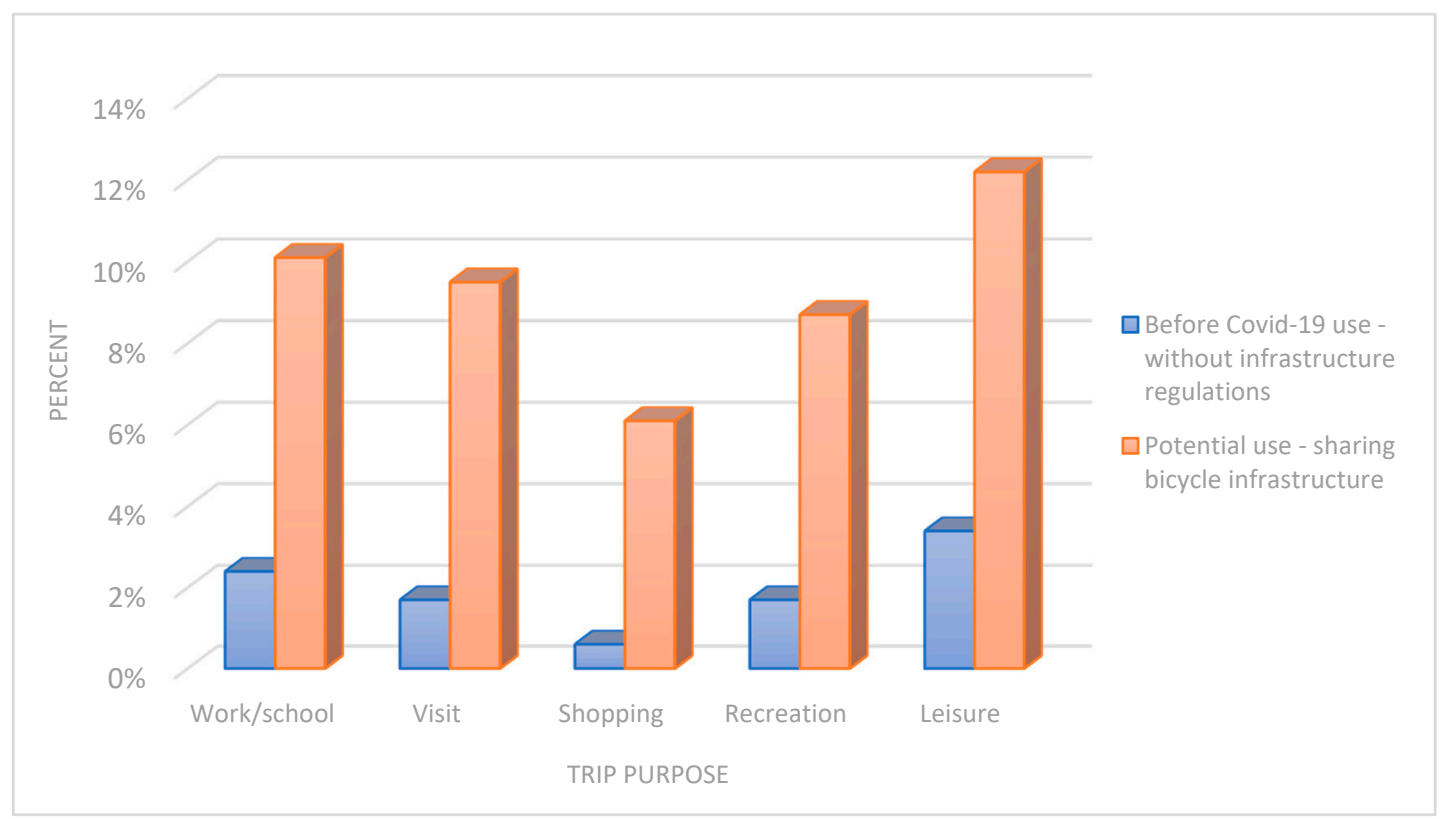

Figure 5. Users' willingness to use e-scooters, by trip purpose, for the most realistic scenario-sharing the infrastructure with cyclists, compared to the use of e-scooters before COVID-19 without infrastructure regulations.

Figure 6 clearly shows the difference in the modal share for the period before and during the pandemic. What is clearly visible in the presented relationship is the increase in the proportion of cars, and the decrease in the proportion of public transport for the reasons already mentioned.

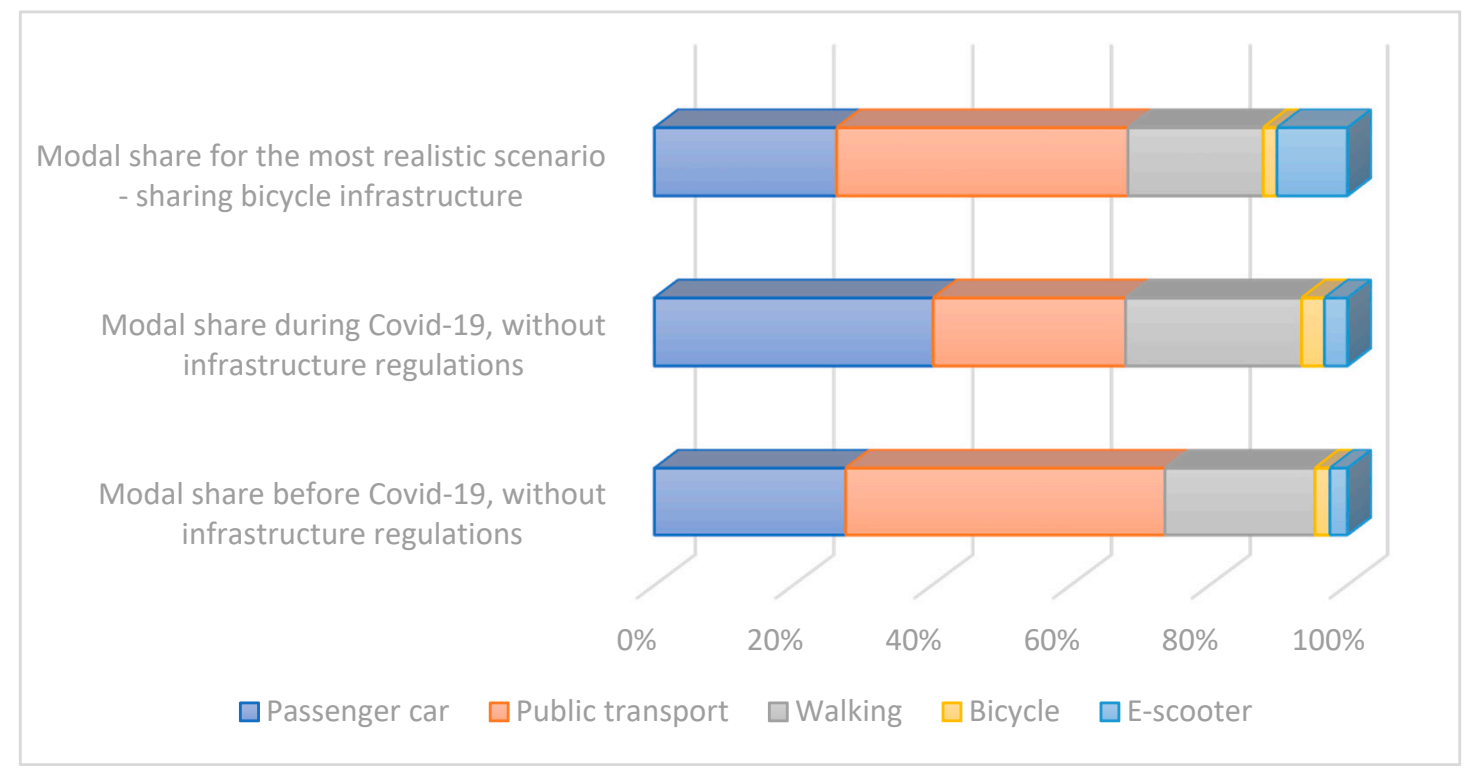

Figure 6. Modal share comparison of the most realistic scenario, where e-scooters share the infrastructure with bicycles, and in the periods during and before the COVID-19 pandemic, without the e-scooter infrastructure regulation.

Although the pandemic has noticeably changed the modal share of certain vehicle categories, this period can be considered a turning point in the process of organizing traffic systems. In the time after the pandemic, which brings various uncertainties, the authors believe that the share of some vehicle categories will tend to regress to the modal share that existed before the pandemic. 
The appearance of the pandemic and the disturbances that have occurred with it are in fact triggers and incentives for changes, the realization of which could further improve traffic systems. An example of such changes is related to the orientation towards nonmotorized users and alternative, sustainable modes of transport. In that sense, the results of this work have shown that the additional "opening up" of the bicycle network for e-scooter users can reduce the proportion of cars in traffic to a certain extent. In this way, potential positive impacts are emphasized, such as the reduction of congestion, emissions, noise, a reduction in space utilization, etc., increasing the sustainability and resilience of cities faced with such emergencies. What is important to mention here is the potentially negative effect of switching to the use of e-scooters. Namely, in Figure 6 it can be noticed that the share of walking and public transport is also reduced alongside a greater use of e-scooters. For this reason, it is necessary to very carefully and thoroughly consider all aspects of the implementation and introduction of e-scooters in traffic systems, to avoid the aforementioned side effects.

The multinomial logistic regression model determined that the variables related to the transport mode used before and during the COVID-19 pandemic, average travel distance, and positive and negative impact factors, were the key variables affecting the users' willingness to shift from other transport modes to e-scooters when traveling for work purposes. The observed scenario for this analysis is a given possibility for e-scooter users to share the infrastructure with cyclists. The positive factors that have a statistically significant impact on the willingness to shift to e-scooters for users that would "maybe" shift are avoiding traffic jams $(p=0.002)$, transport cost savings $(p=0.010)$, physical distancing $(p=0.046)$, affordability $(p=0.025)$ and attractiveness $(p=0.014)$. The negative characteristic for the same group of users is lack of traffic safety when sharing the road with other motor vehicles $(p=0.014)$. The same characteristics are statistically significant for the users that would certainly shift to e-scooters, except for transport cost savings, physical distancing and lack of traffic safety when sharing the road with other motor vehicles. Based on the presented results, the hypothesis $\mathrm{H}_{10}$ can be accepted. Figure 7 shows a summary procedure of the hypothesis testing results, in order to provide an easier understanding of this extensive analysis.

Unlike the research conducted by Riyadh [72], in which statistically significant factors influencing the readiness of users to switch to e-scooters were gender, age and the use of ride-hailing services, this paper did not highlight the abovementioned characteristics. In general, the influencing factors presented in this paper can indicate more clearly the potential measures and activities that should be taken during the regulation and integration of e-scooters. In that sense, the particular significance is perceived in the factors that have a significant positive and negative impact on the willingness of users to use e-scooters, such as regulating the use of e-scooters, providing an adequate and safe infrastructure for these users, and preserving all benefits and advantages offered by e-scooters, primarily the efficiency and flexibility of this mode of transport over shorter distances. Tackling the problem of the integration of e-scooters into transport systems, while preserving the sustainability of cities, requires their treatment at the national level of each country individually, with the prior development of general urban plans, strategies and sustainable urban mobility plans. The specifics of each city, as is the case with Belgrade, require the existence of opportunities and freedom to regulate and treat this type of transport at the local level (city level) in accordance with the existing restrictions and characteristics of the area. 


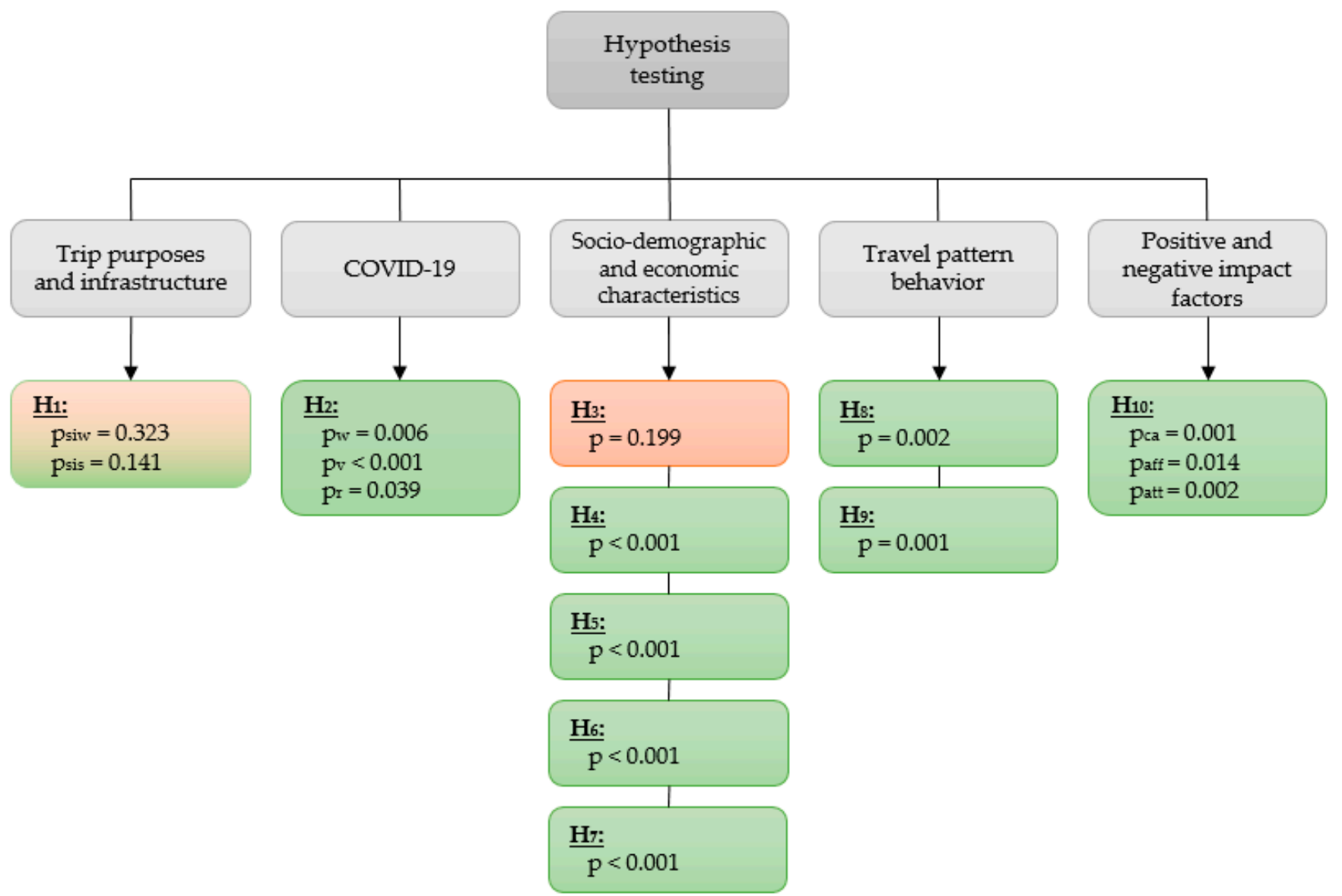

Figure 7. Summary procedure of the hypothesis testing results. Due to the large number of cases tested as part of hypothesis 1, only statistically insignificant results were indicated. The abbreviations in the diagram have the following meaning: psiw $-p$ value in the case of separate infrastructure and sharing infrastructure with cyclists for trips to work/school; psis $-p$ value in the case of separate infrastructure and sharing infrastructure with cyclists for shopping trips; pca- $p$ value in the case of the congestion avoidance impact factor; paff $-p$ value in the case of affordability of e-scooter impact factor; patt $-p$ value in the case of attractiveness of e-scooter impact factor.

\section{Conclusions}

This paper analyzed the pattern characteristics of e-scooter users in Belgrade, the willingness of users to switch to the use of e-scooters, depending on the selected scenario, and factors that affect the users' willingness to switch to e-scooters. The obtained results showed an increase in the use of e-scooters during the pandemic compared to the period before the pandemic for all analyzed trip purposes. Concerning work/school trips, it is important to note that e-scooters are mostly used at distances from 3.0 to $5.0 \mathrm{~km}$, which generally coincides with previous studies conducted on the same topic. This is especially important given the question of the placement of the e-scooter in the traffic system. By implementing e-scooters in traffic, the gap that exists between walking and using public transport can potentially be filled. In that way, the sustainability of the traffic system is enabled on both short and long distances.

In the analysis of hypothetical scenarios that include the availability of a different infrastructure, the obtained results indicated that the use of e-scooters for the analyzed trip purposes would increase by an average of about $9.3 \%$ if e-scooter users were allowed to use the cycling infrastructure. This is an important indicator of the extent to which the availability of an adequate infrastructure would increase e-scooter use.

The analysis of the factors that have a positive or negative impact on the willingness of users to use e-scooters identified several characteristics, provided in the following text. The factors that have the greatest positive impact are environmental protection, avoidance 
of congestion and savings in transportation costs. On the other hand, the factors that have the highest negative impact are primarily related to the regulation of the use of escooters, the non-existence of adequate infrastructure, and the safety of traffic participants. The mentioned positive and negative influencing factors are of great importance in the decision-making process for the regulation and introduction of e-scooters in traffic systems. In general, the provision of an adequate infrastructure is one of the main preconditions for the efficient and safe participation of e-scooters in traffic. In addition, it is necessary to maintain the efficiency and competitiveness of e-scooters over shorter distances, while maintaining the existing percentage of walking but reducing the percentage of car use. Special attention should be paid to strengthening connections with public transport and encouraging multimodal travel. In this way, the advantages of e-scooters are emphasized, while additionally strengthening their place in the traffic system.

The multinomial logistic regression model determined that the variables related to the mode of transport used before and during the COVID-19 pandemic, the average distance traveled, and some positive and negative impact factors were the key variables affecting the users' willingness to shift from other transport modes to e-scooters when traveling for work/school purposes. The presented results confirm nine of the ten hypotheses set out in this paper. Only hypothesis $\mathrm{H} 3$, which analyzes the impact of gender on the willingness to use e-scooters, was rejected. The main aim of this paper is achieved by determining the future impact of e-scooters on the modal share, and determining the factors that influence the users' willingness to switch to e-scooters. Overall, this paper presents important results that can be useful to policymakers, operators and researchers in the process of understanding and integrating e-scooters in traffic systems.

The limitations of this paper are related to several important aspects: the defined sample, research area and categories of vehicles analyzed through this paper. Bearing in mind the appearance of e-scooters all around the world, this new trend needs to be treated primarily at the national and then at the global level. Accordingly, the directions of future research include the expansion of the research area to the entire territory of Serbia, in order to provide relevant data for the entire country, which would increase the sample size and research area. Another important point is that for public transport we considered only buses, trams and trolleybuses, as the most widespread public transport subsystems. Bearing in mind that according to the SmartPlan of Belgrade, the share of motorcycles in the modal share is slightly less than $1 \%$, this type of transport is excluded from the analysis. In accordance with the mentioned limitations, planned future research will include and analyze this specific category of vehicles. It would also be interesting to examine the effects of additional factors, such as the effect of preventive or punitive measures, parking policies and other factors on the willingness of users to use e-scooters.

Author Contributions: Conceptualization, D.G., A.T., M.M. and S.J.; methodology, M.M.; software, M.M.; validation, D.G., A.T., M.M. and S.J.; formal analysis, M.M.; investigation, D.G., A.T., M.M. and S.J.; resources, D.G., A.T., M.M. and S.J.; data curation, D.G., A.T., M.M. and S.J.; writing—original draft preparation, S.J. and M.M.; writing — review and editing, D.G., A.T., M.M. and S.J.; visualization, S.J.; supervision, D.G., A.T., M.M. and S.J. All authors have read and agreed to the published version of the manuscript.

Funding: This research received no external funding.

Institutional Review Board Statement: Not applicable.

Informed Consent Statement: Not applicable.

Data Availability Statement: The data presented in this study are openly available in [FigShare] at [doi] 10.6084/m9.figshare.14627907.

Conflicts of Interest: The authors declare no conflict of interest. 


\section{References}

1. Litman, T. Evaluating Accessibility for Transportation Planning: Measuring People's Ability to Reach Desired Goods and Activities; Victoria Transport Policy Institute: Victoria, BC, Canada, 2012.

2. Department for Transport. Future of Mobility: Urban Strategy; Department for Transport: London, UK, 2019.

3. Colorado Department of Transportation. Mobility Choice Blueprint; Colorado Department of Transportation: Denver, CO, USA, 2019.

4. Hardt, C.; Bogenberger, K. Usage of e-Scooters in Urban Environments. Transp. Res. Procedia 2019, 37, 155-162. [CrossRef]

5. Smith, S.; Schwieterman, J. E-Scooter Scenarios: Evaluating the Potential Mobility Benefits of Shared Dockless Scooters in Chicago. In Proceedings of the Transportation Research Board, Washington, DC, USA, 7-11 January 2018; p. 32.

6. United Nations Department of Economic and Social Affairs/Population Division. World Urbanization Prospects; United Nations Department of Economic and Social Affairs/Population Division: New York, NY, USA, 2018; Volume 12, ISBN 9789211483192.

7. Trivedi, T.K.; Liu, C.; Antonio, A.L.M.; Wheaton, N.; Kreger, V.; Yap, A.; Schriger, D.; Elmore, J.G. Injuries Associated with Standing Electric Scooter Use. JAMA Netw. Open 2019, 2, 9. [CrossRef] [PubMed]

8. Nellamattathil, M.; Amber, I. An evaluation of scooter injury and injury patterns following widespread adoption of E-scooters in a major metropolitan area. Clin. Imaging 2020, 60, 200-203. [CrossRef]

9. Bloom, M.B.; Noorzad, A.; Lin, C.; Little, M.; Lee, E.Y.; Margulies, D.R.; Torbati, S.S. Standing Electric Scooter Injuries: Impact on a Community; Elsevier Inc.: Amsterdam, The Netherlands, 2020.

10. Bekhit, M.N.Z.; Le Fevre, J.; Bergin, C.J. Regional healthcare costs and burden of injury associated with electric scooters. Injury 2020, 51, 271-277. [CrossRef] [PubMed]

11. Gössling, S. Integrating e-scooters in urban transportation: Problems, policies, and the prospect of system change. Transp. Res. Part D Transp. Environ. 2020, 79, 12. [CrossRef]

12. Yang, H.; Ma, Q.; Wang, Z.; Cai, Q.; Xie, K.; Yang, D. Safety of micro-mobility: Analysis of E-Scooter crashes by mining news reports. Accid. Anal. Prev. 2020, 143, 13. [CrossRef] [PubMed]

13. Micromobility, S. 2018. Available online: https://nacto.org/shared-micromobility-2018 (accessed on 3 September 2020).

14. Møller, T.H.; Simlett, J.; Mugnier, E. Micromobility: Moving Cities into a Sustainable Future; EY: London, UK, 2020.

15. Portland Bureau of Transportation. 2018 E-Scooter Findings Report; Portland Bureau of Transportation: Portland, OR, USA, 2019.

16. Chang, A.Y.; Miranda-Moreno, L.; Clewlow, R.; Sun, L. Trend or Fad? Deciphering the Enablers of Micromobility in the U.S.; SAE International: Warrendale, PA, USA, 2019.

17. Populus. The Micro-Mobility Revolution: The Introduction and Adoption of Electric Scooters in the United States; Populus: San Francisco, CA, USA, 2018.

18. Leger, S.; McLaughlin, D.; Tracksdorf, K. Leading the Charge on Canadian E-Bike Integration; WSP: New York, NY, USA, 2018; Volume 7.

19. Department of Transport UK. A Time of Unprecedented Change in the Transport System; Department of Transport UK: London, UK, 2019.

20. Krummel, K.; Gernant, E.; Stolt, R.; Stolze, B.; Moschner, H. Deconstructing the Micromobility Phenomenon; Dr. Ing. h.c. F. Porsche AG: Stuttgart, Germany, 2019.

21. 6t-Bureau de Recherche. Usages et Usagers de Services de Trottinettes Électriques en Free-Floating en France; 6t-Bureau de Recherche: Paris, France, 2019.

22. Bagheri, M.; Mladenović, M.N.; Kosonen, I.; Nurminen, J.K. Analysis of potential shift to low-carbon urban travel modes: A computational framework based on high-resolution smartphone data. Sustainability 2020, 12, 5901. [CrossRef]

23. Burke, M.; Brown, A.L. Distances people walk for transport. Road Transp. Res. 2007, 16, 16-29.

24. Yang, Y.; Diez-Roux, A.V. Walking distance by trip purpose and population subgroups. Am. J. Prev. Med. 2012, 43, 11-19. [CrossRef]

25. City of Santa Monica. Shared Mobility Pilot Program; Office of Planning and Economic Development: Bridgeport, CT, USA, 2019.

26. James, O.; Swiderski, J.I.; Hicks, J.; Teoman, D.; Buehler, R. Pedestrians and e-scooters: An initial look at e-scooter parking and perceptions by riders and non-riders. Sustainability 2019, 11, 5591. [CrossRef]

27. City of Hoboken. Achieving Sustainable Micro-Mobility; Ramboll: Copenhagen, Denmark, 2020.

28. Denver Public Works (DPW). Denver Dockless Mobility Program: Pilot Interim Report; Denver Public Works (DPW): Denver, CO, USA, 2018.

29. Sanders, R.L.; Branion-Calles, M.; Nelson, T.A. To scoot or not to scoot: Findings from a recent survey about the benefits and barriers of using E-scooters for riders and non-riders. Transp. Res. Part A Policy Pract. 2020, 139, 217-227. [CrossRef]

30. City of Santa Monica. Shared Mobility Device Pilot Program; City of Santa Monica Community Development Department: Monica, CA, USA, 2019.

31. Lime San Francisco Scooter Use Survey Results; Lime: San Francisco, CA, USA, 2018.

32. Polis Macro Managing Micro Mobility; POLIS Network: Ixelles, Belgium, 2019.

33. National Association of City Transportation Officials (NACTO). Guidelines for Regulating Shared Micromobility; National Association of City Transportation Officials (NACTO): New York, NY, USA, 2019.

34. Zack, R.; Shapiro, I.; Bailey, C. Micromobility Policy Survey; Remix: San Francisco, CA, USA, 2018. 
35. DuPuis, N.; Griess, J.; Klein, C. Micromobility in Cities. A History and Policy Overview; Vermont League of Cities \& Towns: Montpelier, VT, USA, 2019.

36. Sikka, N.; Vila, C.; Stratton, M.; Ghassemi, M.; Pourmand, A. Sharing the sidewalk: A case of E-scooter related pedestrian injury. Am. J. Emerg. Med. 2019, 37, 1807.e5-1807.e7. [CrossRef] [PubMed]

37. Austin Public Health; City of Austin. Dockless Electric Injuries Study; Austin Public Health: Austin, TX, USA, 2019.

38. Tuncer, S.; Laurier, E.; Brown, B.; Licoppe, C. Notes on the practices and appearances of e-scooter users in public space. J. Transp. Geogr. 2020, 85, 102702. [CrossRef]

39. Brown, A.; Klein, N.J.; Thigpen, C.; Williams, N. Impeding Access: The Frequency and Characteristics of Improper Scooter, Bike, and Car Parking. Transp. Res. Interdiscip. Perspect. 2020, 4, 100099. [CrossRef]

40. Zarif, R.; Pankratz, D.; Kelman, B. Small is Beautiful. Manuf. Eng. 1990, 69, 16-17. [CrossRef]

41. SuSMo. Maximising the Benefits of e-Scooter Deployment in Cities; European Institute of Innovation \& Technology (EIT): Budapest, HU, 2020.

42. Mahoney, L. E-Scooters and Climate Action: Contributions E Potential Risks; C40 Knowledge: London, UK, 2020.

43. O'hern, S.; Estgfaeller, N. A scientometric review of powered micromobility. Sustainability 2020, 12, 9505. [CrossRef]

44. Boglietti, S.; Barabino, B.; Maternini, G. Survey on e-powered micro personal mobility vehicles: Exploring current issues towards future developments. Sustainability 2021, 13, 3692. [CrossRef]

45. Bieliński, T.; Ważna, A. Electric scooter sharing and bike sharing user behaviour and characteristics. Sustainability 2020, $12,9640$. [CrossRef]

46. Tillemann, L.; Feasley, L. Let's Count the Ways E-scooters Could Save the City. Available online: https://www.wired.com/story/ e-scooter-micromobility-infographics-cost-emissions / (accessed on 23 September 2020).

47. Mathew, J.; Liu, M.; Seeder, S.; Li, H.; Bullock, D. Analysis of E-Scooter Trips and Their Temporal Usage Patterns. ITE J. 2019, 44-49. [CrossRef]

48. Invasion of the Electric Scooter: Can Our Cities Cope? The Guardian: London, UK, 2019.

49. National Association of City Transportation Officials (NACTO). Transit Street Design Guide; National Association of City Transportation Officials (NACTO): New York, NY, USA, 2016.

50. Fang, K.; Agrawal, A.; Hooper, A. How and Where Should I Ride This Thing? "RULES of the Road" for Personal Transportation Devices; SJSU Research Foundation: San Jose, CA, USA, 2019.

51. Felton, R. 8 Deaths Now Tied to E-Scooters; CR Consumer Reports: New York, NY, USA, 2019.

52. Austin Public Health. Dockless Electric Scooter-Related Injuries Study; Austin Public Health: Austin, TX, USA, 2018.

53. Sears, N.; Miller, S. Boy, 14, is fighting for his life after crashing e-scooter into a bus stop. Available online: https:/ / www.dailymail. co.uk/news/article-7247303/Boy-14-fighting-life-crashing-electric-scooter-bus-stop.html (accessed on 24 September 2020).

54. Guidance on European Type Approval for Certain Electrically Assisted Pedal Cycles (EAPC); Department for Transport: London, UK, 2017; Volume 4.

55. Fricke, J. Cities now have three choices for how to regulate e-scooters. Available online: https://sifted.eu/articles/jakob-frickesamsung-next-cities-regulation-scooters/ (accessed on 24 September 2020).

56. Urządzenia Transportu Osobistego. Urządzenia Transportu Osobistego. Czekaliśmy na Odpowiedź Resortu i Jest. Prawo Drogowe. 13 February 2019. Available online: https:/ / www.prawodrogowe.pl/informacje/kronika-legislacyjna/urzadzenia-transportuosobistego-czekalismy-na-odpowiedz-resortu (accessed on 24 September 2020).

57. Vehicle Code; Prawo Drogowe: Warsaw, Poland, 2018.

58. Department for Transport. Future of Transport Regulatory Review; Department for Transport: London, UK, 2020.

59. Lukongo, O.E.B. Examining Prominent Causes of Traffic Injury Severity in Louisiana with Multinomial Logistic Models. Transp. Res. Rec. J. Transp. Res. Board 2021, 2675, 245-257. [CrossRef]

60. Ghulam, H.B.; Bhanu, S.J.; Uday, R.R.M. Multinomial Logistic Regression Model for Single-Vehicle and Multivehicle Collisions on Urban, U.S. Highways in Arkansas. J. Transp. Eng. 2012, 138, 12. [CrossRef]

61. Murata, A.; Fujii, Y.; Naitoh, K. Multinomial Logistic Regression Model for Predicting Driver's Drowsiness Using Behavioral Measures. Procedia Manuf. 2015, 3, 2426-2433. [CrossRef]

62. Fan, A.; Chen, X.; Wan, T. How Have Travelers Changed Mode Choices for First/Last Mile Trips after the Introduction of Bicycle-Sharing Systems: An Empirical Study in Beijing, China. J. Adv. Transp. 2019, 2019, 16. [CrossRef]

63. Coughenour, C.; Paz, A.; de la Fuente-Mella, H.; Singh, A. Multinomial logistic regression to estimate and predict perceptions of bicycle and transportation infrastructure in a sprawling metropolitan area. J. Public Health 2015, 38, e401-e408. [CrossRef] [PubMed]

64. Festa, D.C.; Forciniti, C. Attitude towards bike use in Rende, a small town in South Italy. Sustainability 2019, 11, 2703. [CrossRef]

65. Morfoulaki, M.; Tyrinopoulos, Y.; Aifadopoulou, G. Estimation of Satisfied Customers in Public Transport Systems: A New Methodological Approach. J. Transp. Res. Forum 2010, 46, 63-72. [CrossRef]

66. Gupta, K.; Kumar, R.; Neelima, C.; Tomar, S. Multinomial Logistic Regression Modelling for Perception Evaluation of Commuters to Work. In Proceedings of the Conference: Colloquim on Transportation Systems Engineering and Management, Calicut, India, 12-13 May 2014; p. 12.

67. Jenelius, E.; Cebecauer, M. Impacts of COVID-19 on Public Transport Ridership in Sweden: Analysis of Ticket Validations, Sales and Passenger Counts. SSRN Electron. J. 2020, 8, 1-8. [CrossRef] 
68. Nikiforiadis, A.; Paschalidis, E.; Stamatiadis, N.; Raptopoulou, A.; Kostareli, A.; Basbas, S. Analysis of Attitudes and Engagement of Shared e-Scooter Users. Transp. Res. Part D Transp. Environ. 2021, 94, 102790. [CrossRef]

69. Laa, B.; Leth, U. Survey of E-scooter users in Vienna: Who they are and how they ride. J. Transp. Geogr. 2020, 89, 102874. [CrossRef]

70. Dediu, H. The Five Categories of Micromobility; Micromobility Industries: Oakland, CA, USA, 2019.

71. Timić, T.; Glavić, D.; Milenković, M. Micromobility-Vehicles, multimodality, infrastructure. Put i Saobraćaj 2020, 66, 59-64. [CrossRef]

72. Almannaa, M.H.; Alsahhaf, F.A.; Ashqar, H.I.; Elhenawy, M.; Masoud, M.; Rakotonirainy, A. Perception analysis of E-scooter riders and non-riders in Riyadh, Saudi Arabia: Survey outputs. Sustainability 2021, 13, 863. [CrossRef] 